\title{
B Vitamins and n-3 Fatty Acids for Brain Development and Function: Review of Human Studies
}

\author{
Ondine van de Rest ${ }^{a} \quad$ Lenneke W.A. van Hooijdonk $^{b} \quad$ Esmée Doets $^{a}$ \\ Olga J.G. Schiepers ${ }^{c}$ Ans Eilander ${ }^{d}$ Lisette C.P.G.M. de Groot ${ }^{a}$ \\ ${ }^{a}$ Division of Human Nutrition, Wageningen University, Wageningen, ${ }^{b}$ The Netherlands Brain Foundation, \\ The Hague, ' Department of Psychiatry and Neuropsychology, Maastricht University, Maastricht, and ${ }^{\mathrm{d}}$ Unilever R\&D \\ Vlaardingen, Vlaardingen, The Netherlands
}

\section{Key Words}

$\mathrm{n}-3$ fatty acids $\cdot$ B vitamins $\cdot$ Brain $\cdot$ Cognitive function $\cdot$

Cognitive development

\begin{abstract}
Background: Nutrition is one of many factors that affect brain development and functioning, and in recent years the role of certain nutrients has been investigated. B vitamins and $n-3$ polyunsaturated fatty acids (PUFA) are two of the most promising and widely studied nutritional factors. Methods: In this review, we provide an overview of human studies published before August 2011 on how vitamin $B_{6}$, folate, vitamin $B_{12}$ and $n-3$ PUFA may affect the brain, their nutrient status and the existing evidence for an association between these nutrients and brain development, brain functioning and depression during different stages of the life cycle. Results: No recommendation can be given regarding a role of $B$ vitamins, either because the number of studies on B vitamins is too limited (pregnant and lactating women and children) or the studies are not consistent (adults and elderly). For n-3 PUFA, observational evidence may be suggestive of a beneficial effect; however, this has not yet been sufficiently replicated in randomized controlled trials (RCTs). Conclusions: We found that the existing evidence
\end{abstract}

from observational studies as well as RCTs is generally too limited and contradictory to draw firm conclusions. More research is needed, particularly a combination of good-quality long-term prospective studies and well-designed RCTs.

Copyright $\odot 2012$ S. Karger AG, Basel

\section{Introduction}

In recent years, there has been increasing scientific and public interest in the relation between nutrition and brain functioning, and there are indications that diet can affect cognitive development and functioning at different ages and life stages (e.g. fetuses, neonates, infants, young children, adults and elderly). Much attention has been given to the $n-3$ polyunsaturated fatty acids (PUFA) eicosapentaenoic acid (EPA) and docosahexaenoic acid (DHA) and B vitamins, in particular the homocysteine (Hcy)-related vitamins $\mathrm{B}_{6}$, folate and $\mathrm{B}_{12}$, and of all nutrients they have been highlighted as potentially important. However, epidemiological studies and randomized controlled trials (RCTs) often show conflicting results, are too limited in terms of the number of subjects or lack appropriate methodology to draw firm conclusions. Also, mechanisms underlying the effects of nutrients on brain

\section{KARGER \\ Fax +4161306 1234 \\ E-Mail karger@karger.ch}

www.karger.com
(C) 2012 S. Karger AG, Basel

0250-6807/12/0604-0272\$38.00/0

Accessible online at:

www.karger.com/anm
Ondine van de Rest

Division of Human Nutrition

Wageningen University

PO Box 8129, NL-6700 EV Wageningen (The Netherlands)

Tel. +31 317485 867, E-Mail Ondine.vandeRest@wur.nl 
function and development are only beginning to be understood. In this review, we will summarize the current literature on the relation between $B$ vitamins and $n-3$ PUFA and brain functioning.

\section{B Vitamins}

The $B$ vitamins that have been particularly investigated in relation to the brain are vitamin $B_{6}$, folate and vita$\min B_{12}$. They are found especially in unprocessed foods and in meat such as turkey and tuna, liver and meat products [1]. These B vitamins contribute to optimal functioning of the central nervous system through their role as cofactors in numerous catalytic reactions in the human body, which are required for neurotransmitter synthesis and functioning [2-5] and myelination of the spinal cord and brain [5]. Adequate folate status is important for the normal growth of the fetus and for brain development, effects that reflect an influence on nucleotide synthesis, DNA integrity and transcription [6]. Most clearly, folate is involved in brain development through its well-demonstrated role in the formation of the neural tube after conception [7]. Folate may also be required for methylation of phospholipids in neuronal membranes and have an impact on membrane-bound receptors, second messenger systems and ion channels. Folate and also vitamin $\mathrm{B}_{12}$ deficiency may cause pernicious anemia with similar effects on cognitive development and functioning as anemia caused by iron deficiency $[3,4]$. Vitamin $B_{12}$ deficiency can also result in neuropathy through degeneration of nerve fibers and irreversible brain damage, which might mediate the effect on cognition $[8,9]$. Similar to folate, vitamin $B_{12}$ deficiency during pregnancy has also been associated with an increased risk of neural tube defects $[10,11]$. Vitamin $B_{6}$, folate and vitamin $B_{12}$ are also all involved in Hcy metabolism, and deficiencies in one or more of these vitamins may lead to increased levels of Hcy [12], which is also one of the modifiable risk factors for Alzheimer's disease (AD) [13].

\section{n-3 PUFA}

n-3 PUFA (also called omega-3 PUFA) are PUFA in which the first double bond is located at the third carbon atom, counting from the methyl end. n-3 PUFA are present in the diet as $\alpha$-linolenic acid (ALA; C18:3 n-3), of which vegetable oils and nuts are main sources, and as very long-chain PUFA, primarily EPA (C20:5 n-3) and
DHA (C22:6 n-3), which are mainly supplied by (fatty) fish. ALA is an essential fatty acid, which can be converted into EPA and DHA by a series of desaturations and elongations. However, in humans the conversion of ALA to EPA and DHA is very limited; only $5-10 \%$ of ALA is converted into EPA, and 1-5\% of ALA or EPA is converted into DHA [14-18], with an overall conversion rate of $4 \%$ at most [19]. This conversion may also be influenced by the amount of ALA and linoleic acid in the diet [2022 , and it is presently unclear whether conversion of dietary ALA is sufficient to meet optimal DHA requirements under all circumstances. Because EPA and DHA are not efficiently synthesized in humans, it is more effective when they are obtained directly from the diet or supplements (e.g. fish oil capsules). Approximately 25$30 \%$ of the fatty acids in the human brain consist of PUFA, of which the n-3 fatty acid DHA and the n- 6 fatty acid arachidonic acid (AA) are major components and play an important role in the structure and function of cell membranes. DHA and AA are rapidly incorporated into the nervous tissue of the retina and brain during the brain's growth spurt, which mainly takes place from the last trimester of pregnancy up to 2 years of age [23-26]. Beyond development of the central nervous system, n-3 PUFA may influence brain function by means of multiple neuroprotective mechanisms. They may reduce oxidative stress and exert anti-inflammatory effects, and they have been linked with aspects of neuron function, including neurotransmission, membrane fluidity, ion channel and enzyme regulation and gene expression. They also reduce cardiovascular risk factors such as triglyceridemia and cerebral blood flow. Plausible mechanisms are well explained in several reviews [27-29].

Currently, little is known about the interaction between $B$ vitamins and $n-3$ PUFA with regard to cognitive functioning. However, it could be hypothesized that supplementation with B vitamins as well as n-3 PUFA would lead to synergistic improvements in mental performance, because both groups of nutrients play a role in the functioning of the central nervous system, as indicated above. Furthermore, animal studies have indicated that vitamin B6 may enhance the conversion of ALA to DHA, through involvement in the $\delta 6$ desaturation step [30]. Thus, vitamin B6 supplementation may improve the brain's DHA status and subsequently influence cognitive function.

In this review, we will focus on the $B$ vitamins (vitamin $\mathrm{B}_{6}$, folate and vitamin $\mathrm{B}_{12}$ ) and $\mathrm{n}-3$ PUFA in relation to cognitive development, cognitive functioning and mental well-being (depression) throughout the life cycle, i.e. in pregnant and/or lactating women, childhood and in ado- 
lescents and the elderly. Current literature reviews will be summarized with the aim of obtaining a more comprehensive overview and assessing the state of art in order to come to a general and updated consensus. This review will address the following questions for B vitamins and $n-3$ PUFA: (1) what is their nutritional status in the different age groups; (2) what is the evidence for a relation with brain function, which conclusions can be drawn from that evidence and which inconsistencies and limitations can be determined, and (3) what suggestions and recommendations can be provided for future research, based on a careful evaluation and discussion of the current literature?

\section{Methodology}

Medline databases and the Cochrane database were searched up to August 2011 for papers that matched (combinations of) the following search terms: (1) cognition, cognitive decline, cognitive functioning, cognitive development, mental health, mental development, mental well-being, depression or mood; (2) B vitamins, vitamin $B_{6}$, pyridoxine, folate, folic acid, vitamin $B_{12}$ or cobalamin, and (3) fish, omega- 3 fatty acids, $n-3$ fatty acids, docosahexaenoic acid, DHA, eicosapentaenoic acid or EPA. In addition, lists of references in the identified publications were checked. The search was restricted to papers that were written in English, and we used the most recent review papers as a starting point. When no review papers were found or when review papers were published before 2009, original research papers were also included.

We included studies conducted in apparently healthy subjects, and therefore studies in selected subjects with learning disabilities, neuropsychiatric disorders or chronic psychiatric health conditions were excluded. Studies investigating vitamin $\mathrm{B}_{6}$, folate, vitamin $\mathrm{B}_{12}$, EPA and DHA alone or as combinations of these nutrients were included. We excluded studies investigating B vitamins and/or n-3 PUFA in combination with other nutrients. Studies with outcomes on cognitive development and performance and on depression were included. For studies conducted in pregnant and lactating women, we included the effects of the intervention on outcomes in their children and excluded outcomes on cognitive performance or depression in the mothers.

Throughout this review, we have divided the identified literature into three different target groups: (1) pregnant and/or lactating women and effects on their children; (2) infants, children and adolescents, and (3) adults and elderly.

\section{Results}

Our search yielded a total of 88 publications, of which 19 were reviews on $B$ vitamins and 16 were reviews on $n-3$ PUFA. In total, 112 studies on B vitamins and cognitive function and 29 studies on B vitamins and depression were described, as well as 120 studies on n-3 PUFA and cognitive function and 61 studies on n-3 PUFA and depression. No publications were found on studies investigating a combination of $B$ vitamins and $n-3$ PUFA.

\section{B Vitamins}

Recommended Intakes and Nutritional Status of the B Vitamins per Age Group

The recommended daily intakes (RDIs) for vitamin $\mathrm{B}_{6}$, folate and vitamin $\mathrm{B}_{12}$ as established by the Food and Nutrition Board [31], the Health Council of The Netherlands [32] and the EURRECA network [33-35] are shown in table 1.

\section{Pregnant and Lactating Women}

It is confirmed that indicators of vitamin $\mathrm{B}_{6}$ status decrease during pregnancy, especially in the third trimester [36-38]. Studies have suggested that a large percentage of pregnant and lactating women have vitamin $\mathrm{B}_{6}$ intakes between 44 and $61 \%$ of the RDI, and only $6 \%$ met the RDI $[39,40]$. Studies using biochemical indicators of vitamin $\mathrm{B}_{6}$ status confirmed that these low intakes affect the status of mothers and their infants (40-60\% were suboptimal) and vitamin $B_{6}$ concentrations in the breast milk [2, 41]. Pregnant women are at risk of folate deficiency because pregnancy significantly increases the folate requirement, especially during periods of rapid fetal growth (i.e. in the second and third trimester) [42]. During lactation, losses of folate in milk also increase the folate requirement. In several countries, fortification of enriched cereal-grain products with folic acid is mandatory, and in these countries a substantial increase in serum folate concentrations and subsequent decline in neural tube birth defect rates have been observed among women of childbearing age [43]. When pregnant women consume diets providing adequate levels of vitamin $\mathrm{B}_{12}$, the fetus accumulates vitamin $B_{12}$. In contrast, children born to vegetarians or women with a low vitamin $B_{12}$ intake may develop signs of clinical vitamin $B_{12}$ deficiency such as neuropathy. Moreover, higher amounts of vitamin $B_{12}$ are found in milk of lactating women with adequate vitamin 
Table 1. Current recommendations for intakes of vitamin $B_{6}$, folate and vitamin $B_{12}$

\begin{tabular}{|c|c|c|c|c|c|c|c|c|}
\hline \multirow[t]{2}{*}{ Population } & \multirow[t]{2}{*}{ Age group } & \multicolumn{2}{|c|}{ Vitamin $\mathrm{B}_{6}, \mathrm{mg} /$ day } & \multicolumn{2}{|c|}{ Folate, $\mu \mathrm{g} /$ day } & \multicolumn{3}{|c|}{ Vitamin $B_{12}, \mu g /$ day } \\
\hline & & $\mathrm{RDI}^{1}$ & $\mathrm{RDI}(\mathrm{NL})^{2}$ & $\mathrm{RDI}^{1}$ & $\mathrm{RDI}(\mathrm{NL})^{2}$ & $\mathrm{RDI}^{1}$ & $\mathrm{RDI}(\mathrm{NL})^{2}$ & $\begin{array}{l}\text { across } \\
\text { Europe }^{3}\end{array}$ \\
\hline \multirow[t]{2}{*}{ Infants } & $0-6$ months & 0.1 & & 65 & & 0.4 & & $0.3-1.5$ \\
\hline & $7-12$ months & 0.3 & & 80 & & 0.5 & & $0.3-1.5$ \\
\hline \multirow[t]{2}{*}{ Children } & $1-3$ years & 0.5 & & 150 & & 0.9 & & $0.3-1.5$ \\
\hline & $4-8$ years & 0.6 & & 200 & & 1.2 & & $0.3-1.5$ \\
\hline Adolescents & 9-13 years & 1.0 & & 300 & & 1.8 & & $0.8-3.0$ \\
\hline Adults & $14-50$ years & 1.3 & 1.5 & 400 & 300 & 2.4 & 2.8 & $1.4-3.0$ \\
\hline Elderly & $>50$ years & $1.7 / 1.5(\mathrm{M} / \mathrm{F})$ & 1.8 & 400 & 300 & 2.4 & 2.8 & $1.4-3.0$ \\
\hline Pregnant women & NA & 1.9 & 1.9 & 600 & 400 & 2.6 & 3.2 & \\
\hline Lactating women & NA & 2.0 & 1.9 & 500 & 400 & 2.8 & 3.8 & \\
\hline
\end{tabular}

NA $=$ Not applicable. ${ }^{1}$ Food and Nutrition Board. ${ }^{2}$ The Netherlands Nutrition Centre. ${ }^{3}$ EURRECA network.

$\mathrm{B}_{12}$ status, indicating an extra need during lactation. In Guatemala, a high prevalence of deficient and marginal plasma vitamin $\mathrm{B}_{12}$ concentrations was reported in lactating mothers [44].

\section{Infants, Children and Adolescents}

In a small study performed in 35 children aged 3-4 years, $17 \%$ of the children had estimated vitamin $\mathrm{B}_{6}$ intakes less than $2 / 3$ of the RDI and $9 \%$ seemed to have inadequate vitamin $B_{6}$ status as indicated by plasma pyridoxal phosphate levels below $8.5 \mathrm{ng} / \mathrm{ml}$ [45], which is consistent with another study in which deficiency was found in about $10 \%$ of British children [46]. In young British adults, $28 \%$ of males and $37 \%$ of females were deficient [47]. In contrast, in an extensive review of dietary intake and B vitamin status of European adolescents (9-18 years), the mean dietary intake of B vitamins, including vitamin $\mathrm{B}_{6}$, generally exceeded the RDI, except for folate [48]. A possible deficiency of folate was noticed, and girls in particular seemed to be more at risk. Supplements and fortified foods were not taken into consideration by most of the published studies, which distorts the real intake. In another study in 243 young British adults, the status of folate was adequate in most of the cases [47]. Data on the adequacy of vitamin $B_{12}$ intakes in infants, children and adolescents are limited. In general, daily intake of vitamin $B_{12}$ exceeded the estimated average requirements [48]. According to National Health and Nutrition Examination Survey data from 1999-2002, serum concentrations of vitamin $B_{12}$ were $<148 \mathrm{pmol} / \mathrm{l}$ in less than $3 \%$ of children and adolescents [49]. Across studies in Latin America, $40 \%$ of children and adults had a deficient or marginal status, and in African and Asian countries, the reported prevalence of deficient and marginal values might even be as high as $70-80 \%$ due to the low intake of animal-source foods [49].

\section{Adults and Elderly}

It was found that $71 \%$ of males and $90 \%$ of females aged 19-74 years consumed less than the 1980 RDI of vitamin $B_{6}$ [39]. Especially in older people, poor vitamin $B_{6}$ status, approximately $20 \%$ [12], and low dietary vitamin $\mathrm{B}_{6}$ intakes have been observed [50-52]. The trend of lower vitamin $\mathrm{B}_{6}$ status in later life involves low intake, less efficient retention and increased catabolism of the vita$\min [50,51,53]$. Folate deficiency is one of the commonest forms of vitamin deficiency, occurring in about $10 \%$ of the US population [54], in $42 \%$ of healthy older people [12] and in $30-35 \%$ of geriatric patients [55]. However, since folate fortification became mandatory in several countries across the world, serum folate concentrations of middle-aged and older adults have increased [56]. As a consequence, the prevalence of high Hcy concentrations has decreased [43]. There is a high prevalence of low/deficient vitamin $B_{12}$ status among healthy elderly people, which becomes more common with increasing age. Recent population-based studies in Western countries estimated that vitamin $B_{12}$ deficiency affects $5-45 \%$ of the elderly population, depending on the diagnostic criteria used $[49,57,58]$. In less developed countries, the prevalence may be even higher. Although low intake is a potential cause of vitamin $B_{12}$ deficiency, more than $60 \%$ of the low vitamin $\mathrm{B}_{12}$ status found in older people may be due to malabsorption of the vitamin in the gastrointestinal 
tract due to atrophic gastritis or pernicious anemia [49, 59]. For this reason, in the USA people aged $>50$ years are recommended to consume most of their vitamin $B_{12}$ from crystalline $B_{12}$ found in fortified foods and supplements. In this era of folic acid fortification, prevention of vitamin $\mathrm{B}_{12}$ deficiency due to food-bound malabsorption is an important public health issue to be addressed, because high levels of folate may mask anemia related to vitamin $B_{12}$ deficiency, which makes it difficult for the deficiency to be discovered, thus increasing the risk of irreversible neurological damage [58]. It is also important to consider the potential interaction between folate and $B_{12}$ status, because it has been shown that when vitamin $B_{12}$ status is normal, folate supplementation is protective, but in elderly with a suboptimal vitamin $B_{12}$ status, high serum folate was associated with anemia and cognitive impairment $[60,61]$.

\section{Evidence for Effects of B Vitamins on Cognitive Development and Function per Age Group}

\section{Pregnant and Lactating Women}

Observational Evidence

We did not find observational studies that investigated the effect of vitamin $\mathrm{B}_{6}$ alone on cognitive functioning. Only two cross-sectional studies were found on the association between maternal folate concentrations and cognitive ability in offspring. One of these studies assessed cognition in 9- to 10-year-old children in India [62] and the other assessed the mental development of children $<1$ year old in Mexico [63]. Both studies indicated that higher maternal folate concentrations during pregnancy may positively influence their children's cognitive ability. The same two studies also showed that better maternal vitamin $B_{12}$ status during pregnancy may positively influence their children's cognitive ability, but a third cross-sectional study performed in India did not show such an association [62-64].

\section{Trial Evidence}

We did not identify any trials on the effect of vitamin $\mathrm{B}_{6}$, folate or vitamin $\mathrm{B}_{12}$ supplementation in pregnant or lactating women on the cognitive functioning of their offspring.

\section{Infants, Children and Adolescents}

Observational Evidence

We did not find any observational studies on vitamin $\mathrm{B}_{6}$ alone, and only two studies, both performed in India, explored the link between folate status and cognitive performance in toddlers [65] and schoolchildren [66]. Both failed to find a significant association between folate status and cognitive test scores. Four studies have assessed the association between vitamin $B_{12}$ status and cognitive performance in children. The first study, conducted in The Netherlands, showed that infants of 15 months of age from mothers on a macrobiotic diet had a lower vitamin $\mathrm{B}_{12}$ status and delayed motor and language development compared to control children [67]. When these children were 10-16 years of age, those consuming a macrobiotic diet early in life performed less well on cognitive tests measuring fluid intelligence, spatial ability and shortterm memory compared to omnivorous children [68]. A second study in Indian toddlers aged 12-18 months showed a significant positive association between vitamin $B_{12}$ status and mental performance [65]. Similarly, a study conducted in Guatemala demonstrated that 8- to 12 -year-old school children with vitamin $\mathrm{B}_{12}$ deficiency had poorer scores on cognitive tests than children with an adequate status. However, these findings were not controlled for socioeconomic status, hemoglobin, iron status and blood lead levels [69]. In contrast, a fourth study in Indian schoolchildren 6-10 years of age found an inverse association of vitamin $B_{12}$ concentrations with cognitive performance, which remained significant after controlling for hemoglobin and folate status and height-for-age $\mathrm{Z}$ scores [66].

\section{Trial Evidence}

To the best of our knowledge, there are no RCTs that have investigated the effect of vitamin $\mathrm{B}_{6}$ or folate alone on cognitive functioning. Only recently, the effect of vitamin $B_{12}$ supplementation was studied in an RCT in 32 Indonesian children 4-6 years of age [70]. After 6 months of intervention, children consuming $10 \mu \mathrm{g}$ of vitamin $\mathrm{B}_{12}$ daily performed significantly better on memory tests compared to control children.

In summary, there are no studies on vitamin $B_{6}$, and studies on folate are scarce. There are some indications that vitamin $B_{12}$ may benefit children's cognitive development, but only from a limited number of studies. In particular, more RCTs will be needed to conclude whether vitamin B supplementation will improve mental performance in children.

\section{Adults and Elderly}

Observational Evidence

In two reviews, observational studies investigating the association of vitamin $B_{6}$ status with cognitive perfor- 
mance have been described [8, 71]. Two cross-sectional studies and one longitudinal study were included, and except in one cross-sectional study, higher vitamin $\mathrm{B}_{6}$ status was associated with better cognitive performance. A more recent review by Smith [72] included six additional cross-sectional studies and seven prospective studies performed after 2002. Of these additional crosssectional and prospective studies, three did not find an association, whereas the remaining seven (three crosssectional and four prospective) did. Van Dam and Van Gool [13] reviewed high-quality studies (according to a quality scoring list $[73,74]$ ) and identified only one casecontrol study meeting their standards, without a significant association between low vitamin $\mathrm{B}_{6}$ levels and $\mathrm{AD}$. In summary, there is still a lot of controversy in this area and more research is needed.

Raman et al. [75] reviewed evidence from cohort and case-control studies on folate status and cognitive performance. In six out of ten longitudinal and case-cohort studies, low baseline blood folate concentrations in cognitively intact or impaired aging subjects were associated with poorer cognitive test performance at follow-up [75]. The relation between folate levels and $\mathrm{AD}$ was investigated in nine studies, among which four found associations. Van Dam and Van Gool [13] reviewed only 13 highquality (based on a quality scoring list $[73,74]$ ) case-control studies, of which four (three also addressed by Raman et al. [75]) observed lower serum folate levels in AD cases versus controls.

A large number of reviews has been published that report on the relation between vitamin $B_{12}$ and cognitive function. Here, only the results of systematic reviews are summarized. Ellinson et al. [76] summarized the evidence from two case-control and two cohort studies that examined the association between serum vitamin $B_{12}$ and cognitive decline in patients with $\mathrm{AD}$ or vascular dementia. One case-control study reported that among dementia cases, lower cognitive scores were associated with higher serum $B_{12}$ levels. The other case-control study and the two cohort studies did not show any association [76]. Raman et al. [75] reviewed evidence from cohort and case-control studies, including one case-control study also included by Ellinson et al. [76]. Results from eight studies $(n=80-700)$ in cognitively intact or impaired aging subjects showed no clear association between vitamin $\mathrm{B}_{12}$ blood concentrations and changes in performance in any particular cognitive domain during 3-8 years of follow-up. Only two studies reported a significant positive association between baseline vitamin $\mathrm{B}_{12}$ levels and cognitive outcomes at follow-up (memory and visuomotor skills). An association between vitamin $B_{12}$ levels and the risk of $\mathrm{AD}$ could not be demonstrated using data from five prospective and five case-control studies; only one case-control study showed an association [75]. All studies included in the review by Raman et al. [75] were judged for study quality, and all, except for one, were graded fair or poor. Vogel et al. [77] reviewed the evidence from cross-sectional, case-control and longitudinal studies. As all studies reporting on an association between vitamin $\mathrm{B}_{12}$ levels and cognitive outcomes were of cross-sectional or case-control design, the associations found could also result from cognitive impairment, rather than a causal relationship between vitamin $B_{12}$ and cognitive performance [77].

Conclusions from nonsystematic reviews are in line with those from the reviews described above, stating that the direct relation between vitamin $B_{12}$ levels and cognitive function remains unclear [8,78-81]. It is important to note that good-quality studies are lacking, and there is a large variation between studies with regard to cognitive assessment methods (incidence dementia, global cognitive performance or domain-specific cognitive performance tests), cutoff levels for indicating low vitamin $B_{12}$ status, study populations and adjustment for confounders, limiting data supportive of an association [72, 75]. Furthermore, the most commonly used indicator of vitamin $B_{12}$ status is total serum $B_{12}$, whereas methylmalonic acid and holotranscobalamin are more sensitive indicators of functional vitamin $B_{12}$ status in relation to cognition. A case-control study and a cohort study demonstrated that cognitive impairment was associated with methylmalonic acid and holotranscobalamin, whereas no associations with serum $B_{12}$ were found [72]. The reviews summarized here showed inconsistent results with respect to the association between vitamin $\mathrm{B}_{12}$ concentrations and cognitive function.

Results from four studies investigating the relation between dietary intake of all three $B$ vitamins and cognitive test performance or AD did not support an association [75]. A review by Calvaresi and Bryan [8] showed that cross-sectional studies on 71-833 healthy community-dwelling elderly subjects suggested low folate intake or status to be the most reliable associate of cognitive performance either alone or in combination with vitamin $B_{12}$. Results of two longitudinal studies suggested that intake of $\mathrm{B}$ vitamins is a predictor of cognitive status at a later date [8]. Vogel et al. [77] addressed 77 crosssectional studies including more than 34,000 subjects. Results indicated significant associations between low blood levels of vitamin $\mathrm{B}_{12}$ and folate and vascular de- 
mentia, AD and mild cognitive impairment. This association could not be demonstrated in all of a total of 33 longitudinal studies including more than 12,000 subjects. It could be that poor nutritional habits of demented patients explain vitamin B deficiency instead of the other way around [77]. Ellinson et al. [76] considered three case-control studies and three cohort studies examining the association between serum vitamin $B_{12}$, serum folate and total Hcy and cognitive decline in patients with $\mathrm{AD}$ or vascular dementia. The results suggested that cognitive impairment was negatively correlated with Hcy but not consistently with serum $B_{12}$ and serum folate [76]. Low levels of both B vitamins and raised Hcy were also observed in subjects without cognitive impairment, thus not supportive of an association. Ellinson et al. [76] suggest that elevated Hcy may be a consequence of cognitive impairment in elderly people. Dangour et al. [82] included 11 prospective cohort studies in their systematic review and confirmed the lack of any consistent beneficial effect on cognitive function of folic acid with or without vitamin $B_{12}$.

\section{Trial Evidence}

The Cochrane Review of literature on vitamin $\mathrm{B}_{6}$ and cognition published before April 2008 only included two RCTs, one conducted in 211 healthy older women and one in 76 healthy older men [83]. Though oral vitamin $B_{6}$ supplements improved biochemical indices of vitamin $B_{6}$ status in the healthy men, in both studies, no statistically significant effects on cognition were observed. Another review completed by Balk et al. [84] included one additional RCT [85], which also showed no effect. This trial was performed in subjects with ischemic vascular disease, and follow-up cognitive testing was performed 9 months after the vitamin supplementation was stopped. Another RCT not included in the Cochrane Review, but included in the review of Calvaresi and Bryan [8], did find a positive effect of vitamin $B_{6}$ supplementation on visual reproduction [86]. No trials of vitamin $\mathrm{B}_{6}$ involving individuals with cognitive impairment or dementia were found. There is insufficient trial evidence to support any dose effect or differences in effect on cognitive domains. More well-designed RCTs are needed to explore possible benefits from vitamin $B_{6}$ supplementation for healthy older people and also for those with cognitive impairment or dementia.

Balk et al. [84] included three RCTs on the effects of folic acid supplementation on cognitive function. None of these studies observed significant effects compared to placebo. For several cognitive tests, net improvements were shown, and therefore they conclude that there is limited evidence, but it may suggest a benefit from folic acid supplementation for people with cognitive impairment and low folate levels. In 2005, Malouf included four RCTs in a Cochrane Review and found no evidence for an effect of folic acid on cognitive functioning. This Cochrane Review was updated in 2008 and now eight RCTs were included [87]. Out of four RCTs performed in healthy elderly, one found a beneficial effect of folic acid supplementation. The four other RCTs were performed in cognitively impaired people, and again only one showed a beneficial effect. In two RCTs, folic acid was supplemented together with vitamin $B_{12}$, but neither showed an effect. The most recent meta-analysis focusing on the effects of folic acid supplementation with or without other $B$ vitamins on cognitive function in non-cognitively impaired elderly is from Wald et al. [88], and the most recent systematic review is from Dangour et al. [82]. The same four RCTs on folic acid supplementation were addressed as discussed above, leading to the same conclusion of no effect.

A Cochrane Review [89] including three RCTs ( $\mathrm{n}=$ 11-141) on the effect of vitamin $B_{12}$ supplementation on cognitive function of people with low serum vitamin $B_{12}$ revealed no effect. Balk et al. [84] addressed evidence from six RCTs ( $\mathrm{n}=18-70$; two trials were also included in the Cochrane Review) on 35 tests in subjects with either normal or impaired cognitive function. Half of the tests found a net but not clinically relevant improvement in cognitive function and the other half found a net worsening of cognitive function with vitamin $\mathrm{B}_{12}$ supplementation. There was no evidence across RCTs of differences in effects in tests of different cognitive domains. Moretti et al. [79] summarized results from good-quality intervention studies performed in cognitively impaired or demented subjects and concluded that vitamin $\mathrm{B}_{12}$ supplementation may improve language function but will not cure dementia. This conclusion is in line with a review by Wang [81] showing positive effects of vitamin $B_{12}$ supplementation in subjects with mild dementia or a short history of dementia (four studies), whereas no effects were found among severely demented patients or demented patients of mixed severity (three studies).

Balk et al. [84] and Dangour et al. [82] included six $\mathrm{RCTs}$ on the effect of combined B vitamin intervention, of which two RCTs were also included in the Cochrane Review of Malouf and Grimley Evans [87]. Two studies used a combination of vitamin $\mathrm{B}_{6}$, folic acid and vitamin $\mathrm{B}_{12}$, and four other studies combined folic acid and vita- 
min $B_{12}$. For most of the cognitive tests, no effect was found with $B$ vitamin treatment. This result is in line with other reviews showing no effect of vitamin $B_{12}$ supplementation in combination with folate and vitamin $B_{6}$ (one and seven RCTs, respectively) $[8,77]$. A very recent RCT in 299 hypertensive men aged 75 years and over did not observe a benefit of 2-year daily supplementation of vitamin $\mathrm{B}_{6}, \mathrm{~B}_{12}$ and folic acid on cognitive function in older men, nor did this regime reduce the risk of cognitive impairment or dementia 8 years later [90].

In summary, RCTs have showed inconsistent results. However, it must be noted that there is a large variation between trials with regard to doses, administration routes (e.g. oral or intramuscular), study populations and duration of treatments, which complicates drawing firm conclusions regarding the effects of vitamin $B_{12}$ supplementation.

\section{Hcy and Optimal Cognitive Development and Function}

Elevated plasma Hcy was associated with cognitive decline in several studies $[13,72,75,77,80]$ and predicted the subsequent development of dementia in cognitively intact middle-aged and elderly individuals [91]. It was suggested that moderately elevated concentrations of Hcy and/or low to normal concentrations or intake of folate, vitamin $B_{6}$ and vitamin $B_{12}$ increase the risk of developing cognitive impairment and dementia in older populations $[8,72]$. The review by Clarke [78] revealed an association between baseline Hcy and subsequent cognitive decline based on prospective studies of individuals without dementia. Moreover, elevated Hcy levels were associated with brain atrophy. The review raised the possibility that vitamin $B_{12}$ may have an effect on the risk of dementia that is independent of differences in plasma Hcy [78]. Van Dam and van Gool [13] provided a systematic analysis of observational studies fulfilling the criteria of a high-quality scoring list $[73,74]$ on the relation between elevated levels of Hcy and AD. The results suggested that levels of Hcy in $\mathrm{AD}$ are indeed higher and that this is most probably caused by lower folate, vitamin $B_{12}$ and possibly also vitamin $B_{6}$ levels during disease [13]. It is not yet clear whether the observed associations of Hcy with cognitive function are caused by Hcy itself, independent actions of folate, vitamin $\mathrm{B}_{6}$ or vitamin $\mathrm{B}_{12}$ by means of lowering Hcy, or by a combination [77].

B Vitamins and n-3 Fatty Acids and Mental Health

\section{B Vitamins in Relation to Depression}

\section{Pregnant and Lactating Women/Infants, Children} and Adolescents

Observational Evidence

We did not find any observational studies that examined the effect of $\mathrm{B}$ vitamins on depression in the offspring of pregnant and lactating women, and we found only one observational, cross-sectional study performed in 3,067 Japanese boys and 3,450 girls aged 12-15 years. This study suggests that higher intake of dietary B vitamins, particularly folate and vitamin $\mathrm{B}_{6}$, is independently associated with a lower prevalence of depressive symptoms in early adolescence [92].

\section{Trial Evidence}

We did not find any RCTs that examined the effect of $B$ vitamins on depression in pregnant and lactating women or in infants, children or adolescents.

\section{Adults and Elderly}

Observational Evidence

Few studies have examined the association of only vitamin $B_{6}$ with depression. Some cross-sectional studies observed an association of vitamin $\mathrm{B}_{6}$ status with depression $[93,94]$, but others did not [95]. Some recent crosssectional studies observed associations between folate status and depressive symptoms [95-97], whereas others did not $[98,99]$. Results of studies that assessed the association between vitamin $B_{12}$ and depression were also controversial, some showing a significant association between a better status and less depression $[95,96,98]$ and some not $[97$, 99]. A prospective study with up to 12 years of follow-up showed that high total intakes of vitamin $\mathrm{B}_{6}$ and folate as well as vitamin $B_{12}$ are protective against depressive symptoms over time [100]. The observation that $\mathrm{B}$ vitamins and total Hcy may be associated with depression was first described in the 1970s by Reynolds et al. [101]. Nine crosssectional studies were combined in a meta-analysis by Almeida et al. [102] to investigate the association between total Hcy and depression in later life. Generally, high plasma total Hcy was associated with an increase in the odds of depression. However, more recent cross-sectional studies did not observe an association between Hcy levels and depression [97-99]. Data from a recent prospective study showed only moderate support for the hypothesis that blood Hcy is a predictor of depression [103].

Altogether, evidence from observational studies for a link between depression and either one of the Hcy-lowering B vitamins or plasma Hcy on its own is mixed.

Ann Nutr Metab 2012;60:272-292 
Trial Evidence

In the Cochrane Review on vitamin $\mathrm{B}_{6}$ and cognition, the effect of vitamin $B_{6}$ on mood was also reported. Based on the two trials that fulfilled the criteria, no evidence for short-term benefit was found [83]. In 2005, Williams et al. [104] evaluated the evidence on vitamin $B_{6}$ supplementation as treatment for depression and included five RCTs. One had to be excluded, and of the four remaining RCTs, two observed a treatment effect of vitamin $B_{6}$.

Almeida et al. [102] reported on the effects of Hcylowering treatment on depression. Of the five RCTs included, four used supplementation with folic acid only and one with vitamin $B_{12}$ only. All showed an antidepressant effect, although the number of patients studied was small and the reported benefits associated with B vitamin treatment were mostly based on post hoc comparisons of subgroups of patients. Ford et al. [105] supplemented 299 men of $>75$ years with a combination of vitamin $B_{6}$, folic acid and vitamin $B_{12}$ for a period of 2 years, but the results of this study showed that $B$ vitamin treatment was not better than placebo for reducing depressive symptoms. A very recent trial by Almeida et al. [106] in poststroke patients observed that long-term treatment (mean 7.1 years) with folic acid, vitamin $B_{6}$ and vitamin $B_{12}$ was associated with a reduction in the hazard of major depression. A larger trial, aiming to include 300 adults $>60$ years who will be supplemented with vitamin $B_{6}$, folate and vitamin $\mathrm{B}_{12}$ or placebo for 12 weeks, is currently ongoing [90]. The results from clinical trials to date are modest at best and do not adequately support the findings of observational research.

In summary, the number of studies that have investigated the relation of $\mathrm{B}$ vitamins with depression is limited, especially in pregnant and/or lactating women and infants, children and adolescents.

\section{n-3 PUFA}

\section{Recommended Intakes and Nutritional Status of n-3} PUFA per Age Group

The recommended EPA + DHA values that have been proposed by different organizations are globally in the range of 200-600 mg/day [107]. Information has accumulated from observational and intervention studies with pregnant and lactating women, and with infants fed formula, that under some circumstances, higher dietary intakes of n-3 PUFA are needed [108]. However, specific dietary recommendations in such circumstances are cur- rently unknown. One study showed that an n-3 PUFA intake of $0.4 \mathrm{en} \%(900 \mathrm{mg} / \mathrm{day} / 2,000 \mathrm{kcal})$ from seafood was likely to meet the nutritional requirements of $97.5 \%$ of the mothers and children. These considerations may contribute to the formulation of specific RDIs [109]. Harmful contaminants, such as mercury, accumulate in fish, but similar to the general population, it is also the case for pregnant and lactating women that the benefits of modest fish intake, excepting a few selected species, outweigh the risks [110]. Furthermore, there are indications that requirements may also be altered by certain gene polymorphisms, such as variations in FADS1 and FADS2 [111].

\section{Pregnant and Lactating Women}

DHA (and also AA) are highly incorporated into the developing brain of the fetus during the prenatal period, and sufficient evidence is available to conclude that maternal fatty acid nutrition is important for DHA transfer to the infant before and after birth, with short- and longterm implications for neural function [111]. However, this transfer is probably at the expense of the status of the mother as the overall maternal n-3 PUFA status declines steadily during pregnancy [112]. Therefore, the question arises whether the mother, under the prevailing dietary conditions, is able to meet the high fetal requirement for n-3 PUFA [112]. However, in very early pregnancy, maternal plasma and erythrocyte phospholipid 22:6 n-3 concentrations start to increase, which cannot be explained by changes in dietary intake alone. This rise probably represents early maternal adaptations to meet the requirements of highly proliferating and differentiating tissues of the fetus [113].

\section{Infants, Children and Adolescents}

Specific dietary recommendations for EPA and DHA in these age groups are currently unknown, and it is unclear whether dietary ALA intake is sufficient for optimal cognitive development. In the majority of countries worldwide, intakes of ALA are below the recommendations of the WHO [114]. Compared to adults, conversion rates are lower in infants, in particular those born premature, and because of its critical role in the development of the brain and retina, additional DHA is recommended early in life [115-117].

\section{Adults and Elderly}

There is a large variation in intake of EPA + DHA across studies and countries, but in most Western populations, intakes are far below recommendations. In the USA and Europe, the mean intake of EPA + DHA varies 
between 100 and $500 \mathrm{mg}$ per day [118-121], while in Japan intakes are around $1 \mathrm{~g}$ per day [121]. Average fish intake of the general Dutch population as estimated in 1998 was only $10 \mathrm{~g}$ per day [122], especially in older men, of whom $28 \%$ did not consume fish at all and $41 \%$ consumed $>20$ g per day, but only $11 \%$ comprised fatty fish [123]. With aging, n-3 PUFA concentrations in brain tissues appear to decrease $[124,125]$, and also, cognitively impaired and demented individuals have decreased blood levels of $n-3$ PUFA $[126,127]$. The underlying cause of these changes is largely unknown and could be related to inefficient conversion of precursors (linoleic acid and ALA) to long-chain PUFA or a high n-6 fatty acid intake and/or reduced n-3 PUFA intake, but also to impaired $\Delta-6$ and $\Delta-5$ desaturase activity or increased lipid peroxidation [116]. Also, genetic factors have to be taken into account. Several studies suggest that effects of DHA may be genotype specific; protection by DHA may be limited in noncarriers of the apolipoprotein E (APOE) 4 allele of the APOE genotype, probably through different transport or metabolism of n-3 PUFA [128, 129].

\section{Evidence for Effects of n-3 PUFA on Cognitive Development and Function per Age Group}

\section{Pregnant and Lactating Women}

Observational Evidence

In 2008, Hadders-Algra [130] reviewed studies on the effect of n-3 PUFA or fish consumption by women during pregnancy on the neurodevelopmental outcomes of their children. The results of these studies suggest that prenatal DHA status may have a subtle positive effect on neurodevelopmental outcomes, also beyond early infancy [130]. More recently performed studies $(n=8)$ were included in the review by Ryan et al. [131], and six linked higher intakes of fish in pregnant women to higher scores on tests of cognitive function in their children at ages between 18 months and 14 years.

\section{Trial Evidence}

In the review of Eilander et al. [132], which was published in 2007, seven RCTs on n-3 PUFA supplementation in pregnant and/or lactating women and the effect on the cognitive development of their children were identified. Based on these studies, it was concluded that there is suggestive evidence for a beneficial effect of supplementation during pregnancy and/or lactation on mental development and on longer-term cognition. However, the effects were small and inconsistent. Hoffman et al. [133] and Ryan et al. [131] also included most of the studies in their reviews, and they also suggest that dietary DHA may be relevant for cognitive functioning. Hadders-Algra [130] includes some additional studies (probably because of using less strict inclusion criteria) and is more careful by concluding that the effects are limited but that there may be a subtle beneficial effect.

\section{Infants, Children and Adolescents}

Observational Evidence

Epidemiological studies on the association of $n-3$ PUFA intake and cognitive performance in childhood are listed in the review by Ryan et al. [131], and three out of the five studies showed a beneficial association.

\section{Trial Evidence}

In 2001, Simmer [134] concluded in a Cochrane Review that, based on seven RCTs in term infants, there was little evidence for a benefit of $n-3$ PUFA supplementation on general neural development in the first 36 months of life. After this review, there were nine new RCTs on n-3 PUFA supplementation in full-term infants, which were reviewed by Eilander et al. [132] in 2007. They concluded that based on these nine RCTs, there is hardly evidence for beneficial effects. Simmer et al. [135] updated their Cochrane Review in 2008, and additional studies were described in the review by Hoffman et al. [133] in 2009. Thus, more studies were included, but they came to the same conclusion and acknowledge that there was significant variation among the various studies regarding the type, concentration and duration of supplementation with n-3 PUFA and that higher levels of DHA may play a role in achieving beneficial effects.

Eilander et al. [132] also searched for RCTs investigating the effects of n-3 PUFA on cognitive performance in children after the age of 2 , and in 2007 , no such RCTs were identified. However, since then, seven RCTs in older, healthy children without developmental disorders, such as attention deficit hyperactivity disorder, have assessed the effect of n-3 PUFA on cognitive function. One of them was conducted in preschool children aged 4 years [136] and the others in children aged 6-10 years [137142]. Three of these studies investigated the effect of EPA + DHA or DHA only compared to a placebo, and none found any beneficial effects of supplementation on cognitive function following a low dose of $110 \mathrm{mg}$ of EPA + DHA [142] for 1 year, a dose of $400 \mathrm{mg}$ of DHA for 4 months [136] or with higher dosages of 400 and $1,000 \mathrm{mg}$ of DHA for 8 weeks [138]. Similarly, a fourth study comparing the effect of either a low (140 mg of ALA) or high 
dose (900 mg of ALA plus $100 \mathrm{mg}$ of DHA) of n-3 PUFA for 12 months showed no differences between groups [141]. A fifth study [139] showed that out of 37 outcomes on cognitive and behavioral tests, there were three differences between the group receiving $228 \mathrm{mg}$ of EPA + DHA plus vitamins $\mathrm{A}, \mathrm{C}, \mathrm{D}$ and $\mathrm{E}$ for 8 weeks and the control group. One of the three differences was in favor of the control group. In contrast, however, a sixth study did find an increase in prefrontal cortex activation during sustained attention using functional magnetic resonance techniques following 400 and 1,200 mg of DHA for 8 weeks [140]. Also, the seventh study showed that children receiving an $\mathrm{n}$-3-rich fish flour spread had better scores on verbal learning and memory tests compared to those receiving a control spread [137]. However, it is possible that other nutrients in addition to the n-3 PUFA in the fish flour contributed to the cognitive effects. Six of these RCTs (all except that of Kirby et al. [139]) were included in an update of the review by Ryan et al. [131].

Overall, there is little evidence for a beneficial effect of EPA plus DHA on cognitive function in healthy children. More specific and sensitive measures of brain function may be needed to detect the relatively small effects of $n-3$ PUFA. Furthermore, the doses used may have been too low $[141,142]$ or the duration of treatment may have been too short $[136,138]$ to reveal the effects of EPA and DHA on children's cognitive function.

\section{Adults and Elderly}

Observational Evidence

De Groot et al. [143] performed an exploratory study to investigate the potential association between fatty acid status and cognitive performance in a healthy, nonpregnant adult population and observed that, as in pregnant women, higher DHA levels were associated with a slower learning effect. Furthermore, not much information is available about fatty acid status and cognitive performance in healthy adults aged 20-40 years. Most of the evidence for an association between n-3 PUFA and cognition in older people originates from a number of different epidemiological investigations. The association of fish and EPA + DHA consumption with cognitive decline and dementia has been examined in different populations, both cross-sectionally and prospectively. There are several reviews providing a good overview of the current evidence. All report separately on studies using fish or n-3 PUFA intake and studies using biochemical indicators for assessment of n-3 fatty acid status.

In 2009, Cunnane et al. [129] identified three crosssectional and nine prospective studies (follow-up 2-21 years) that reported on fish or n-3 PUFA intake and the risk of cognitive decline, dementia or AD. The majority of the studies observed that higher intake decreased the risk, and they conclude that this evidence is a fairly solid basis for believing that low fish and DHA intake contribute significantly to the risk of AD. Based on the observations in seven prospective studies with a follow up of 3-9 years and 15 cross-sectional studies using blood measures of DHA status, they conclude that lower blood DHA is also fairly convincingly linked to a higher risk of cognitive decline and AD.

Cederholm and Palmblad [144] reviewed only 'recent' literature on the potential role of n-3 PUFA in cognitive decline and AD. Their review, based on 13 recent observational studies (five cross-sectional and eight prospective), of which seven used biochemical indicators and nine dietary assessment of $n-3$ PUFA, indicates that, although a number of observational studies have been published in recent years, no firm conclusions can be drawn on the role of $n-3$ PUFA in the prevention and treatment of cognitive decline, dementia and $\mathrm{AD}$. The evidence is only fairly consistent, but still fish or DHA intake may be a preventive option at the population level and may emerge, especially DHA, as an adjuvant treatment for selected individuals in early $\mathrm{AD}$.

The most extensive review, by Huang [128], reports on nine cross-sectional studies, of which five out of the six studies that examined blood or plasma n-3 PUFA and all three that examined dietary n-3 PUFA in relation to cognitive functioning in $\mathrm{AD}$ and dementia found that better outcomes were associated with higher $n-3$ PUFA. In total, 27 prospective studies were found, of which 19 examined fish or n-3 PUFA intake and nine examined plasma or erythrocyte n-3 PUFA with regard to dementia, AD and cognitive decline. Again, the majority of the associations showed protective effects against dementia, AD or cognitive decline, which is also consistent with a very recent 13-year prospective study [145]. Nonsignificant effects may have been due to the amount and type of fish consumed. The most recent systematic review by Dangour et al. [82] included only prospective studies with $\mathrm{AD}$ as end point and found eight studies (six also included in the previously mentioned reviews), of which only two reported reduced $\mathrm{AD}$ and dementia incidence.

\section{Trial Evidence}

In 2006, the latest review of the Cochrane Collaboration was published and yielded only two RCTs in demented elderly and none in cognitively healthy elderly [146]. The first RCT was small in terms of sample size $(n=20)$ 
and the second one was of short duration (4 weeks) [147, 148]. Since then, several larger and longer RCTs have been performed, both in healthy as well as cognitively impaired elderly.

The review of Cederholm and Palmblad [144] on 'recent' evidence describes the results of three RCTs, one in 302 healthy Dutch elderly [149], one in 174 subjects with mild to moderate AD [150] and a small RCT in Taiwan including 46 subjects with mild to moderate $\mathrm{AD}$ and mild cognitive impairment [151]. The first two RCTs, both with a study duration of 6 months, observed no overall effect, except in post hoc analyses in a subgroup of men and carriers of the APOE 4 allele [149] or in those with the mildest forms of AD. The third trial showed better cognitive outcomes after n-3 PUFA treatment for 24 weeks. Dangour et al. [82] included only RCTs that fulfilled the Cochrane Collaboration guidelines, which comprised four RCTs, three of them also included in the other reviews and one not fulfilling our criteria because there was no EPA + DHA treatment intervention group.

In the review of Cunnane et al. [129] and the very recent review of Huang [128], the same RCTs were included, and they additionally included an exploratory preventive RCT in 49 healthy elderly [152] and some small exploratory trials in patients with various forms of dementia. Most of the RCTs did not observe any change in cognitive performance after n-3 PUFA treatment, leading to the conclusion that based on these eight RCTs, at best a very modest clinical benefit of n-3 PUFA has been reported, and suggest that supplementation may be more effective in more vulnerable subjects who have not yet been diagnosed with AD. Fotuhi et al. [153] discussed four RCTs in their systematic review, all of which were also included in at least one of the previously mentioned reviews and all of which also failed to show an effect.

However, some more recent large RCTs were not included in these reviews. An 18-month RCT in subjects with mild to moderate AD $(n=402)$ showed no treatment effect of $2 \mathrm{~g}$ of DHA/day on cognitive function tests [154]. Improved learning and episodic memory functions after 6 months of supplementation with $900 \mathrm{mg}$ of algal DHA/ day were observed in 485 elderly with memory complaints [155]. The largest and longest RCT to date, performed in 867 cognitively healthy adults aged 70-79 years, showed no significant differences in cognitive functions after 24 months of supplementation with 200 $\mathrm{mg}$ of EPA + $500 \mathrm{mg}$ of DHA [156]. Even though these larger and well-performed trials are an important addition to the total body of evidence, still no definitive conclusion can be drawn. However, the studies do suggest that RCTs should be targeted to subjects who are vulnerable but have not yet been diagnosed with AD. The results of a large, ongoing intervention study planning to enroll 1,200 frail older adults who will be supplemented with n-3 PUFA for a period of 3 years are awaited [157].

\section{n-3 PUFA in Relation to Depression}

\section{Pregnant and Lactating Women}

We only found a few observational studies and trials that focused on maternal mental well-being, but none on the effect of the mother's n-3 PUFA status on their offspring's mental well-being.

\section{Infants, Children and Adolescents}

Observational Studies

Ramakrishnan et al. [158] identified no observational studies in healthy children in their recent review, only in children with attention deficit hyperactivity disorder and in children with behavioral problems, which are beyond the scope of this review. Mamalakis et al. [159] investigated n-3 PUFA in adipose tissue of adolescents aged 1318 years. Initially they did not observe an association between n-3 PUFA and depression scores [159], but when they included serum adiponectin as a predictor variable, they observed a negative association between EPA in adipose tissue and depression [160].

\section{Trial Evidence}

Ramakrishnan et al. [158] also identified no RCTs in their recent review, only in children with attention deficit hyperactivity disorder and in children with behavioral problems. However, in 2006 an RCT investigating n-3 PUFA treatment in 28 children aged 6-12 years was performed and observed that n-3 PUFA may have therapeutic benefits in childhood depression [161]. Also, Osher et al. [162] performed an RCT in 28 children of the same age and showed highly significant effects of $\mathrm{n}-3$ treatment on different depression rating scales.

In this area, there is a lack of observational evidence and RCT evidence is very limited. More observational studies and more and larger RCTs are needed before a conclusion can be drawn.

\section{Adults and Elderly}

Observational Evidence

n-3 PUFA have often been related to depressive symptoms. Early epidemiological evidence for the involvement of n-3 PUFA in depression was provided by an ecological 
study which reported a negative correlation between national fish consumption and the annual prevalence of major depression [163]. Since then, various populationbased studies have been performed, and their results were summarized by Appleton et al. [164] in 2008. Most studies suggested a beneficial role for fish or n-3 PUFA intake in depression [164]. Some more recent studies did [165] or did not [166] observe an association between fish consumption or n-3 PUFA intake and depressive symptoms, and in one study associations were only found in women [167]. To the best of our knowledge, there is only one prospective study, which suggests a potential benefit of moderate n-3 PUFA intake after 2 years of follow-up [168].

Appleton et al. [164] also included clinical studies investigating the associations between n-3 PUFA status and depressive illness in their review. The majority of these studies found reduced n-3 PUFA concentrations in individuals suffering from depression compared with healthy persons [164]. In addition, a recent meta-analysis focusing on 14 studies evaluating differences in fatty acid status between depressed patients and controls has indicated that EPA, DHA and total n-3 PUFA levels were significantly lower in depressed patients, whereas there were no differences in n-6 PUFA [169].

Furthermore, various studies assessing n-3 PUFA status in population-based samples have reported an inverse association between n-3 PUFA status and depressed mood in community-dwelling individuals with depressive symptoms above the clinical threshold $[170,171]$. However, no associations between n-3 PUFA status and depressive symptoms were observed when taking into account the full range of depressive symptomatology as occurring in the general population [171, 172], which suggests that $n-3$ PUFA status may be normal in individuals showing only mild symptoms of depressed mood, whereas suboptimal n-3 PUFA levels may accompany more severe depressive symptomatology.

\section{Trial Evidence}

Intervention studies examining the effects of $n-3$ PUFA supplementation on depressive symptoms have yielded heterogeneous results. Whereas a number of RCTs have shown that treatment with EPA and/or DHA may be effective in alleviating depressive symptoms in patients suffering from major depression, other studies have not found any effect of n-3 PUFA treatment on depressive symptoms. Completed RCTs were included in a systematic review and meta-analysis in which it was concluded that differences in study duration, placebo comparison and n-3 PUFA dose may have contributed to the observed discrepancies between results and that this heterogeneity also hampered comparison and evaluation of the studies [173]. Another recent meta-analysis including 28 RCTs has suggested that the contrasting results may be related to the differential efficacy of EPA and DHA in reducing depressive symptomatology; supplements containing over 50\% EPA were more effective in the treatment of depressive illness than those consisting primarily of DHA [174]. RCTs in population-based samples have generally failed to demonstrate a beneficial effect of n-3 PUFA supplementation on depressed mood [173], which is consistent with the reported lack of associations between $n-3$ PUFA status and subclinical depressive symptoms in the general population. The most recent RCT, performed in depressed elderly patients, showed a beneficial effect of n-3 PUFA treatment on depressive symptoms [175].

Altogether, despite substantial heterogeneity between study findings, the results from epidemiological studies, clinical studies and RCTs suggest that a low n-3 PUFA status may be involved in depressive illness and that depressed patients might benefit from supplementation with n-3 PUFA, and EPA in particular. On the other hand, the involvement of n-3 PUFA in subclinical manifestations of depressed mood appears to be negligible.

\section{Discussion}

We reviewed the available data from observational studies as well as RCTs that investigated B vitamins and n-3 PUFA in relation to cognitive development, cognitive functioning and mental well-being throughout the life cycle. In table 2, the findings of all studies included in this review are summarized, to provide an overview of the number of studies that has been published and their results. Based on all the studies together, we can conclude that:

- With regard to the cognitive development and mental well-being of pregnant and/or lactating women and their offspring, there are currently no (vitamin $\mathrm{B}_{6}$ ) or only very few cross-sectional studies (folate and vita$\min B_{12}$ ). Therefore, this area needs more observational studies as well as RCTs before recommendations can be made. For n-3 PUFA, a fair number of observational studies as well as RCTs have been performed; however, results are controversial. Thus, the role of $n-3$ PUFA remains inconclusive.

- With regard to the cognitive development, cognitive functioning and mental well-being of infants, children and adolescents, no (vitamin $\mathrm{B}_{6}$ ) or only very few ob- 
Table 2. Summary of the main findings of the studies included in this review

\begin{tabular}{|c|c|c|c|c|}
\hline Nutrient & Population & Evidence & Main findings: cognition & Main findings: depression \\
\hline \multirow[t]{4}{*}{ Vitamin $\mathrm{B}_{6}$} & $\begin{array}{l}\text { pregnant and lactating } \\
\text { women }\end{array}$ & $\begin{array}{l}\text { observational } \\
\text { RCTs }\end{array}$ & $\begin{array}{l}\text { no studies } \\
\text { no studies }\end{array}$ & $\begin{array}{l}1 \mathrm{CS} \text { : beneficial association } \\
\text { no studies }\end{array}$ \\
\hline & $\begin{array}{l}\text { infants, children and } \\
\text { adolescents }\end{array}$ & $\begin{array}{l}\text { observational } \\
\text { RCTs }\end{array}$ & $\begin{array}{l}\text { no studies } \\
\text { no studies }\end{array}$ & $\begin{array}{l}1 \mathrm{CS} \text { : beneficial association } \\
\text { no studies }\end{array}$ \\
\hline & adults and elderly & observational & $\begin{array}{l}9 \text { CS: } 4 \text { beneficial association } \\
8 \text { prospective: } 5 \text { positive }\end{array}$ & $\begin{array}{l}3 \text { CS: } 2 \text { beneficial association } \\
1 \text { prospective: positive }\end{array}$ \\
\hline & & RCTs & 4 RCTs: 1 beneficial effect & 6 RCTs: 2 beneficial effect \\
\hline \multirow[t]{4}{*}{ Folate } & $\begin{array}{l}\text { pregnant and lactating } \\
\text { women }\end{array}$ & $\begin{array}{l}\text { observational } \\
\text { RCTs }\end{array}$ & $\begin{array}{l}2 \text { CS: } 2 \text { beneficial association } \\
\text { no studies }\end{array}$ & $\begin{array}{l}\text { no studies } \\
\text { no studies }\end{array}$ \\
\hline & $\begin{array}{l}\text { infants, children and } \\
\text { adolescents }\end{array}$ & $\begin{array}{l}\text { observational } \\
\text { RCTs }\end{array}$ & $\begin{array}{l}2 \text { CS: neither beneficial } \\
\text { no studies }\end{array}$ & $\begin{array}{l}\text { no studies } \\
\text { no studies }\end{array}$ \\
\hline & adults and elderly & observational & $\begin{array}{l}8 \mathrm{CS} \text { : all beneficial association } \\
31 \text { prospective: } 15 \text { positive }\end{array}$ & $\begin{array}{l}5 \text { CS: } 3 \text { beneficial association } \\
1 \text { prospective: negative }\end{array}$ \\
\hline & & RCTs & 6 RCTs: 2 beneficial effect & 4 RCTs: 4 beneficial effect \\
\hline \multirow[t]{5}{*}{ Vitamin $\mathrm{B}_{12}$} & $\begin{array}{l}\text { pregnant and lactating } \\
\text { women }\end{array}$ & $\begin{array}{l}\text { observational } \\
\text { RCTs }\end{array}$ & $\begin{array}{l}3 \text { CS: } 2 \text { beneficial association } \\
\text { no studies }\end{array}$ & $\begin{array}{l}\text { no studies } \\
\text { no studies }\end{array}$ \\
\hline & $\begin{array}{l}\text { infants, children and } \\
\text { adolescents }\end{array}$ & observational & $\begin{array}{l}3 \text { CS: } 2 \text { beneficial association } \\
1 \text { prospective: positive }\end{array}$ & no studies \\
\hline & & RCTs & 1 RCT: beneficial effect & no studies \\
\hline & adults and elderly & observational & 28 prospective: 7 beneficial association & $\begin{array}{l}5 \text { CS: } 3 \text { beneficial association } \\
1 \text { prospective: negative }\end{array}$ \\
\hline & & RCTs & 6 RCTs: 0 beneficial effect & 1 RCT: 1 beneficial effect \\
\hline \multirow[t]{5}{*}{ n-3 PUFA } & $\begin{array}{l}\text { pregnant and lactating } \\
\text { women }\end{array}$ & observational & $\begin{array}{l}2 \text { CS: } 2 \text { beneficial association } \\
14 \text { prospective: } 9 \text { positive }\end{array}$ & no studies for offspring \\
\hline & & RCTs & 17 RCTs: 8 beneficial effect & no studies for offspring \\
\hline & $\begin{array}{l}\text { infants, children and } \\
\text { adolescents }\end{array}$ & $\begin{array}{l}\text { observational } \\
\text { RCTs }\end{array}$ & $\begin{array}{l}5 \text { CS: } 3 \text { beneficial association } \\
33 \text { RCTs: } 10 \text { beneficial effect }\end{array}$ & $\begin{array}{l}1 \text { CS: } 1 \text { beneficial association } \\
2 \text { RCTs: } 2 \text { beneficial effect }\end{array}$ \\
\hline & adults and elderly & observational & $\begin{array}{l}9 \text { CS: } 6 \text { beneficial association } \\
28 \text { prospective: } 21 \text { positive }\end{array}$ & $\begin{array}{l}21 \mathrm{CS}: 17 \text { beneficial association } \\
1 \text { prospective: positive }\end{array}$ \\
\hline & & RCTs & 12 RCTs: 6 beneficial effect & 36 RCTs: 18 beneficial effect \\
\hline
\end{tabular}

CS = Cross-sectional study

servational studies (folate and vitamin $\mathrm{B}_{12}$ ) and only one RCT (vitamin $B_{12}$ ) have been performed, together providing too limited evidence to draw a conclusion. For n-3 PUFA, there are only few observational studies but many RCTs on cognition, most of which do not support a beneficial effect. Studies on mental well-being are too few to draw a conclusion.

- With regard to cognitive performance and cognitive impairment in adults and elderly, the most studies were found in this group. For the B vitamins, a fair number of observational studies have been conducted, especially on the role of folate and vitamin $\mathrm{B}_{12}$, but evidence is mostly not supportive. RCTs are limited and mostly show no evidence. The number of studies on mental well-being is less abundant, though they mostly support a beneficial effect. For n-3 PUFA and cognitive impairment as well as mental well-being, the numerous observational studies mostly show a beneficial association, whereas RCTs are inconclusive. Based on epidemiological data, n-3 PUFA could be advised; however, whether or not their effect is causal remains to be resolved.

\section{Limitations and Considerations of the Current Data}

While reviewing the evidence and comparing the studies, several considerations had to be taken into account. There is a large heterogeneity between the studies 
with respect to the populations studied, sample size, dose of the treatment, possible combination and interaction with other treatments, administration routes, study duration, methodology used for assessment of cognitive functioning and mental well-being, methodology used for assessment of nutrient intake or nutrient status, a lack of standardized cutoff values indicating low B vitamin nutritional status and the occurrence of confounders. The inconsistent findings from the available studies may be due to these differences or possibly a combination of them and make comparison difficult. Furthermore, the studies are of different quality, which has not been taken into account in this review. This is principally a review of reviews, and we found many inconsistencies in the number and kind of studies included per review. This was often due to slightly different criteria for inclusion or exclusion of studies, but often the criteria used were not clearly described. The focus of this review was primarily on healthy people; however, in many reviews healthy individuals as well as individuals with cognitive impairment or other brain-related disorders or other disorders were all considered together. Thus, we could not always exclude individuals with mental disorders in our overview.

\section{Optimizing Nutrition for Mental Performance or Delaying/Preventing Disease}

The focus of this review was on healthy people, brain development and maintenance of brain functioning with aging. However, it is questionable how large the role of nutrition and certain nutrients may be, especially on top of the complete and diverse diet that we consume. A larger impact is to be expected in individuals with a suboptimal nutrient status and/or in individuals who are in a stage of life in which an optimal supply of nutrients is more critical. In addition, it might be that effects of interventions with $B$ vitamins or n-3 PUFA alone may not become apparent when intakes of other nutrients are inadequate. The implications of a nutrient deficiency on cognitive outcomes will also depend on the stage of development (i.e. deficiencies early in life may have irreversible consequences for cognition later in life) and the severity and duration of the deficiency. There are indeed critical periods during which the brain is more vulnerable to an inadequate diet, such as during the rapid rate of growth of the brain during the last trimester of pregnancy and the first 2 years of life [176, 177]. Another critical period is at the other end of the life span, with the onset and development of age-related cognitive decline. Besides the fact that every individual has a different level of cognitive functioning, there is also a difference in the onset and rate of cognitive decline, which indicates that factors other than aging, such as nutrition, are of influence as well. Prospective studies as well as RCTs aim to examine the prevention and/or delay of cognitive decline. A controversy here may be that typically an RCT is relatively short, but at the same time a relatively high dose of the nutrient, often above what is consumed within a usual diet, is supplemented. This is in contrast with prospective studies, where more habitual feeding patterns are studied over a particular period of usually several years. Feeding patterns that have already existed for years may already have exerted their influence on brain health and cognitive reserve, so the effect of supplementation has to be strong to show an effect on top of that.

\section{Recommendations for Future Research}

We agree with the conclusions of several previous reviews that clearly more research is needed and have some suggestions and directions for future research. With regard to the kind of studies, there is need for more longterm observational studies and RCTs. Observational studies should be of sufficiently long duration and include subjects whose dietary information is available at a sufficiently early stage or at least before disease or cognitive decline exist. These studies must control for the known confounding factors and incorporate multiple tests of cognition and multiple assessment periods. RCTs should be well designed, of sufficient duration, with adequate numbers of subjects and preferably include specific types of individuals who may be more responsive to treatment effects, such as elderly with cognitive impairment (e.g. Mild Cognitive Impairment patients), subjects with a suboptimal status of one or more nutrients or subjects with certain genotypes such as the APOE4 genotype. One limitation of RCTs may be that the exposure time for the specific nutrient may need to be very long before effects appear. Nevertheless, it is of utmost importance that well-designed RCTs are executed.

Studies are preferably designed in a more similar way with respect to, for instance, treatment, kind of subjects included and measurement of cognitive functioning, in order to enable comparisons between studies and, when sufficient studies are performed and published, to combine the studies in proper meta-analyses to obtain a more powerful estimation of the effect size. 
The focus should not only be on whether a factor plays a role or not, but also on establishing how the nutrient could be biologically linked. Consideration and knowledge of individual differences and genetic factors underlying sensitivity to nutrient effects are necessary for more effective and valuable strategies. New techniques for investigating nutritional influences on the brain, such as brain imaging techniques, should also be explored.

Furthermore, a more integrated approach using whole diet as opposed to a reductionist approach by addressing exposure to specific dietary constituents is recommended. This could also be a suitable basis for population guidelines on healthy food intake and would be a more efficient approach in combating multiple age-related diseases, because overlapping biological mechanisms may be affected. Moreover, there is a growing need for nutrient-dense diets once energy intake and needs decline with progressing age, and special attention should be given to specific nutrients that are of concern, because the supply may be hindered by poor endogenous synthesis and/or hindered absorption.

\section{Conclusion}

Despite several plausible biochemical mechanisms, the evidence from observational studies as well as RCTs is generally limited and too inconsistent to draw firm conclusions. No recommendation can be given regarding a role of $\mathrm{B}$ vitamins on the brain. For $\mathrm{n}-3$ PUFA, obser- vational evidence may be suggestive of a beneficial effect; however, this was not replicated in most RCTs to date. The research field is far from having reached satiation, particularly with regard to studies investigating the nutrient status of pregnant and/or lactating mothers and the subsequent effects on their offspring, as well as studies focusing on infants, children and adolescents. Although many more studies have been performed in adults and especially the elderly, still more studies are needed because of the inconsistent results. In particular, more longterm prospective studies and well-designed RCTs (to prove a causal effect) are needed.

In conclusion, more research is needed before definitive guidelines for the use of B vitamins and/or n-3 PUFA for brain development, functioning and maintenance can be provided because current evidence is insufficient and lacks consistency.

\section{Acknowledgment}

This work was commissioned by The Netherlands Brain Foundation, which also partly financially supported the final preparation of the manuscript by the corresponding author (O.R.).

\section{Disclosure Statement}

Ans Eilander is an employee of Unilever. Unilever markets foods of which some are fortified with n-3 PUFA and B vitamins.

\section{References}

1 Stipanuk MH: Biochemical, Physiological and Molecular Aspects of Human Nutrition. St. Louis, Saunders Elsevier, 2006.

$\checkmark 2$ Guilarte TR: Vitamin B6 and cognitive development: recent research findings from human and animal studies. Nutr Rev 1993; 51:193-198.

-3 Hutto BR: Folate and cobalamin in psychiatric illness. Compr Psychiatry 1997;38:305314.

4 Sugden C: One-carbon metabolism in psychiatric illness. Nutr Res Rev 2006;19:117-136.

5 Dror DK, Allen LH: Effect of vitamin B12 deficiency on neurodevelopment in infants: current knowledge and possible mechanisms. Nutr Rev 2008;66:250-255.

6 Reynolds E: Vitamin B12, folic acid, and the nervous system. Lancet Neurol 2006;5:949960

B Vitamins and n-3 Fatty Acids and Mental Health
7 Fleming A: The role of folate in the prevention of neural tube defects: human and animal studies. Nutr Rev 2001;59:S13-S20, discussion S21-S23.

8 Calvaresi E, Bryan J: B vitamins, cognition, and aging: a review. J Gerontol B Psychol Sci Soc Sci 2001;56:P327-P339.

-9 Smith AD, Refsum H: Vitamin B-12 and cognition in the elderly. Am J Clin Nutr 2009;89: 707S-711S.

10 Refsum H: Folate, vitamin B12 and homocysteine in relation to birth defects and pregnancy outcome. Br J Nutr 2001;85(suppl 2):S109-S113.

11 Molloy AM, Kirke PN, Brody LC, Scott JM, Mills JL: Effects of folate and vitamin B12 deficiencies during pregnancy on fetal, infant, and child development. Food Nutr Bull 2008; 29:S101-S111, discussion S112-S115.
12 Selhub J, Jacques PF, Wilson PW, Rush D, Rosenberg IH: Vitamin status and intake as primary determinants of homocysteinemia in an elderly population. JAMA 1993;270: 2693-2698.

13 Van Dam F, Van Gool WA: Hyperhomocysteinemia and Alzheimer's disease: a systematic review. Arch Gerontol Geriatr 2009;48: 425-430.

14 Pawlosky RJ, Hibbeln JR, Novotny JA, Salem $\mathrm{N}$ Jr: Physiological compartmental analysis of alpha-linolenic acid metabolism in adult humans. J Lipid Res 2001;42:1257-1265.

15 Burdge GC, Jones AE, Wootton SA: Eicosapentaenoic and docosapentaenoic acids are the principal products of alpha-linolenic acid metabolism in young men. Br J Nutr 2002;88:355-363. 
16 Burdge GC, Wootton SA: Conversion of alpha-linolenic acid to eicosapentaenoic, docosapentaenoic and docosahexaenoic acids in young women. Br J Nutr 2002;88:411-420.

17 Gerster H: Can adults adequately convert alpha-linolenic acid (18:3n-3) to eicosapentaenoic acid (20:5n-3) and docosahexaenoic acid (22:6n-3)? Int J Vitam Nutr Res 1998;68: 159-173.

-18 Goyens PL, Spilker ME, Zock PL, Katan MB, Mensink RP: Compartmental modeling to quantify alpha-linolenic acid conversion after longer term intake of multiple tracer boluses. J Lipid Res 2005;46:1474-1483.

-19 Brenna JT: Efficiency of conversion of alphalinolenic acid to long chain n-3 fatty acids in man. Curr Opin Clin Nutr Metab Care 2002; 5:127-132.

20 Vermunt SH, Mensink RP, Simonis MM, Hornstra G: Effects of dietary alpha-linolenic acid on the conversion and oxidation of 13C-alpha-linolenic acid. Lipids 2000;35: 137-142.

-21 Goyens PL, Spilker ME, Zock PL, Katan MB, Mensink RP: Conversion of alpha-linolenic acid in humans is influenced by the absolute amounts of alpha-linolenic acid and linoleic acid in the diet and not by their ratio. Am J Clin Nutr 2006;84:44-53.

-22 Emken EA, Adlof RO, Gulley RM: Dietary linoleic acid influences desaturation and acylation of deuterium-labeled linoleic and linolenic acids in young adult males. Biochim Biophys Acta 1994;1213:277-288.

23 Dobbing J, Sands J: Quantitative growth and development of human brain. Arch Dis Child 1973;48:757-767.

-24 Clandinin MT, Chappell JE, Leong S, Heim T, Swyer PR, Chance GW: Extrauterine fatty acid accretion in infant brain: implications for fatty acid requirements. Early Hum Dev 1980;4:131-138.

-25 Clandinin MT, Chappell JE, Leong S, Heim T, Swyer PR, Chance GW: Intrauterine fatty acid accretion rates in human brain: implications for fatty acid requirements. Early Hum Dev 1980;4:121-129.

26 Martinez M: Tissue levels of polyunsaturated fatty acids during early human development. J Pediatr 1992;120:S129-S138.

-27 Cole GM, Ma QL, Frautschy SA: Omega-3 fatty acids and dementia. Prostaglandins Leukot Essent Fatty Acids 2009;81:213-221.

-28 Schmitz G, Ecker J: The opposing effects of n-3 and n-6 fatty acids. Prog Lipid Res 2008; 47:147-155.

-29 Young G, Conquer J: Omega-3 fatty acids and neuropsychiatric disorders. Reprod Nutr Dev 2005;45:1-28.

-30 Smit EN, Muskiet FA, Boersma ER: The possible role of essential fatty acids in the pathophysiology of malnutrition: a review. Prostaglandins Leukot Essent Fatty Acids 2004;71: 241-250.
31 Food and Nutrition Board, Institute of Medicine, National Academy of Sciences: Dietary Reference Intakes for Thiamin, Riboflavin, Niacin, Vitamin B6, Folate, Vitamin B12, Pantothenic Acid, Biotin, and Choline. Washington, National Academy Press, 1998.

32 Health Council of the Netherlands: Towards an Adequate Intake of Vitamins and Minerals. The Hague, Health Council of the Netherlands, 2009.

33 Doets EL, Cavelaars AEJM, DhonuksheRutten RAM, van 't Veer P, de Groot LCPGM: Explaining the variability in recommended intakes of folate, vitamin B12, iron and zinc for adults and elderly people. Public Health Nutr 2012;15:906-915.

34 Hermoso M, Tabacchi G, Iglesia-Altaba I, Bel-Serrat S, Moreno-Aznar LA, GarciaSantos Y, Del Rosario Garcia-Luzardo M, Santana-Salguero B, Pena-Quintana L, Serra-Majem L, Hall Moran V, Dykes F, Decsi T, Benetou V, Plada M, Trichopoulou A, Raats MM, Doets EL, Berti C, Cetin I, Koletzko B: The nutritional requirements of infants. Towards EU alignment of reference values: the EURRECA network. Matern Child Nutr 2010;6(suppl 2):55-83.

35 Iglesia I, Doets E, Bel-Serrat S, Roman B, Hermoso M, Pena Quintana L, Vucic V, Frost Andersen L, Lillegaard IT, Perez-Rodrigo C, Aranceta J, Cavelaars A, Decsi T, Serra-Majem LL, Gurinovic M, Cetin I, Koletzko B, Moreno LA: Physiological and public health basis for assessing micronutrient requirements in children and adolescents. The EURRECA network. Matern Child Nutr 2010;6:84-99.

36 Shane B, Contractor SF: Vitamin $\mathrm{B}_{6}$ status and metabolism in pregnancy; in Tryfiates GP (ed): Vitamin $B_{6}$ Metabolism and Role in Growth. Westport, Food \& Nutrition Press, 1980, pp 137-171.

37 Cleary RE, Lumeng L, Li T-K: Maternal and fetal plasma levels of pyridoxal phosphate at term: adequacy of vitamin B6 supplementation during pregnancy. Am J Obstet Gynecol 1975;121:25-28.

38 Lumeng L, Cleary RE, Wagner R, Yu P-L, Li T-K: Adequacy of vitamin B6 supplementation during pregnancy: a prospective study. Am J Clin Nutr 1976;29:1376-1383.

39 Kant AK, Block G: Dietary vitamin B-6 intake and food sources in the US population: NHANES II, 1976-1980. Am J Clin Nutr 1990;52:707-716.

40 Reynolds RD, Polansky M, Moser PB: Analyzed vitamin B-6 intakes of pregnant and postpartum lactating and nonlactating women. J Am Diet Assoc 1984;84:13391344.

41 Heller S, Salkeld RM, Korner WF: Vitamin B6 status in pregnancy. Am J Clin Nutr 1973; 26:1339-1348.

-42 McPartlin J, Halligan A, Scott JM, Darling M, Weir DG: Accelerated folate breakdown in pregnancy. Lancet 1993;341:148-149.
43 Rader JI: Folic acid fortification, folate status and plasma homocysteine. J Nutr 2002;132: 2466S-2470S

44 Casterline JE, Allen LH, Ruel MT: Vitamin B-12 deficiency is very prevalent in lactating Guatemalan women and their infants at three months postpartum. J Nutr 1997;127: 1966-1972.

45 Fries ME, Chrisley BM, Driskell JA: Vitamin B6 status of a group of preschool children. Am J Clin Nutr 1981;34:2706-2710.

46 Gregory RL, Lowe S: National Diet and $\mathrm{Nu}-$ trition Survey: Young People Aged 4-18 Years. London, The Stationery Office, 2000.

47 Benton D, Haller J, Fordy J: The vitamin status of young British adults. Int J Vitam Nutr Res 1997;67:34-40

48 Al-Tahan J, Gonzalez-Gross M, Pietrzik K: B-vitamin status and intake in European adolescents. A review of the literature. Nutr Hosp 2006;21:452-465.

49 Allen LH: How common is vitamin B-12 deficiency? Am J Clin Nutr 2009;89:693S696S.

50 Kant AK, Moser-Veillon PB, Reynolds RD: Effect of age on changes in plasma, erythrocyte, and urinary B-6 vitamers after an oral vitamin B-6 load. Am J Clin Nutr 1988;48: 1284-1290.

51 Lowik MR, van den Berg H, Westenbrink S, Wedel M, Schrijver J, Ockhuizen T: Doseresponse relationships regarding vitamin B-6 in elderly people: a nationwide nutritional survey (Dutch Nutritional Surveillance System). Am J Clin Nutr 1989;50:391399.

52 Rose CS, Gyorgy P, Butler M, Andres R, Norris AH, Shock NW, Tobin J, Brin M, Spiegel $\mathrm{H}$ : Age differences in vitamin B6 status of 617 men. Am J Clin Nutr 1976;29:847-853.

53 Bates CJ, Pentieva KD, Prentice A, Mansoor MA, Finch S: Plasma pyridoxal phosphate and pyridoxic acid and their relationship to plasma homocysteine in a representative sample of British men and women aged 65 years and over. Br J Nutr 1999;81:191-201.

54 Senti FR, Pilch SM: Analysis of folate data from the second National Health and Nutrition Examination Survey (NHANES II). J Nutr 1985;115:1398-1402.

55 Bottiglieri T, Crellin R, Reynolds EH: Folate and neuropsychiatry; in Bailey LB (ed): Folate in Health and Disease. New York, Dekker, 1994, 435-463.

56 Pfeiffer CM, Caudill SP, Gunter EW, Osterloh J, Sampson EJ: Biochemical indicators of $B$ vitamin status in the US population after folic acid fortification: results from the $\mathrm{Na}$ tional Health and Nutrition Examination Survey 1999-2000. Am J Clin Nutr 2005;82: 442-450.

57 McLean E, de Benoist B, Allen LH: Review of the magnitude of folate and vitamin B12 deficiencies worldwide. Food Nutr Bull 2008; 29:S38-S51. 
58 McNulty H, Scott JM: Intake and status of folate and related B-vitamins: considerations and challenges in achieving optimal status. Br J Nutr 2008;99(suppl 3):S48-S54.

59 Dali-Youcef N, Andres E: An update on cobalamin deficiency in adults. QJM 2009;102: 17-28.

60 Morris MS, Jacques PF, Rosenberg IH, Selhub J: Folate and vitamin B-12 status in relation to anemia, macrocytosis, and cognitive impairment in older Americans in the age of folic acid fortification. Am J Clin Nutr 2007; 85:193-200.

61 Selhub J, Morris MS, Jacques PF, Rosenberg IH: Folate-vitamin B-12 interaction in relation to cognitive impairment, anemia, and biochemical indicators of vitamin B-12 deficiency. Am J Clin Nutr 2009;89:702S-706S.

-62 Veena SR, Krishnaveni GV, Srinivasan K, Wills AK, Muthayya S, Kurpad AV, Yajnik CS, Fall $\mathrm{CH}$ : Higher maternal plasma folate but not vitamin B-12 concentrations during pregnancy are associated with better cognitive function scores in 9- to 10-year-old children in South India. J Nutr 2010;140:1014-1022.

63 del Rio Garcia C, Torres-Sanchez L, Chen J, Schnaas L, Hernandez C, Osorio E, Portillo MG, Lopez-Carrillo L: Maternal MTHFR $677 \mathrm{C}>\mathrm{T}$ genotype and dietary intake of folate and vitamin $\mathrm{B}(12)$ : their impact on child neurodevelopment. Nutr Neurosci 2009;12: 13-20.

64 Bhate V, Deshpande S, Bhat D, Joshi N, Ladkat R, Watve S, Fall C, de Jager CA, Refsum H, Yajnik C: Vitamin B12 status of pregnant Indian women and cognitive function in their 9-year-old children. Food Nutr Bull 2008;29:249-254.

65 Strand TA, Sunita T, Bhandari N, Schneede J, Refsum H, Ueland PM, Bahl R, Sommerfelt HM, Bhan MK: Vitamin B12, but not folate status predicts mental development scores in North Indian toddlers. Ann Nutr Metab 2009;55:691-692.

-66 Eilander A, Muthayya S, van der Knaap H, Srinivasan K, Thomas T, Kok FJ, Kurpad AV, Osendarp SJ: Undernutrition, fatty acid and micronutrient status in relation to cognitive performance in Indian school children: a cross-sectional study. Br J Nutr 2010;103: 1056-1064.

67 Dagnelie PC, van Staveren WA: Macrobiotic nutrition and child health: results of a population-based, mixed-longitudinal cohort study in The Netherlands. Am J Clin Nutr 1994;59:1187S-1196S.

-68 Louwman MW, van Dusseldorp M, van de Vijver FJ, Thomas CM, Schneede J, Ueland PM, Refsum H, van Staveren WA: Signs of impaired cognitive function in adolescents with marginal cobalamin status. Am J Clin Nutr 2000;72:762-769.

-69 Allen LH, Penland JG, Boy E, DeBaessa Y, Rogers LM: Cognitive and neuromotor performance of Guatemalan schoolers with deficient, marginal, and normal plasma vitamin B-12. FASEB J 1999;13:A544.
70 Hardinsyah R, Hardinsyah ZL, Syarief H, Jalal F: Memory level of preschool children is effected by vitamin B12 supplementation. Ann Nutr Metab 2009;55:328.

71 Nourhashemi F, Gillette-Guyonnet S, Andrieu S, Ghisolfi A, Ousset PJ, Grandjean H, Grand A, Pous J, Vellas B, Albarede JL: Alzheimer disease: protective factors. Am J Clin Nutr 2000;71:643S-649S.

72 Smith AD: The worldwide challenge of the dementias: a role for B vitamins and homocysteine? Food Nutr Bull 2008;29:S143-S172.

73 Sutton A, Abrams K, Jones D, Sheldon T, Song F: Methods for Meta-Analysis in Medical Research. Wiley Series in Probability and Mathematical Statistics. New York, Wiley, 2000, pp 57-86.

74 Khan KS, ter Riet G, Glanville J, Sowden AJ, Kleijnen J: Undertaking Systematic Reviews of Research on Effectiveness: CRD's Guidance for Those Carrying out of Commissioning Reviews. York, University of York, NHS Centre for Reviews and Dissemination, 2001.

75 Raman G, Tatsioni A, Chung M, Rosenberg IH, Lau J, Lichtenstein AH, Balk EM: Heterogeneity and lack of good quality studies limit association between folate, vitamins B-6 and B-12, and cognitive function. J Nutr 2007;137:1789-1794.

76 Ellinson M, Thomas J, Patterson A: A critical evaluation of the relationship between serum vitamin $B$, folate and total homocysteine with cognitive impairment in the elderly. J Hum Nutr Diet 2004;17:371-383, quiz 385387.

77 Vogel T, Dali-Youcef N, Kaltenbach G, Andres E: Homocysteine, vitamin B12, folate and cognitive functions: a systematic and critical review of the literature. Int J Clin Pract 2009;63:1061-1067.

78 Clarke R: B-vitamins and prevention of dementia. Proc Nutr Soc 2008;67:75-81.

79 Moretti R, Torre P, Antonello RM, Cattaruzza T, Cazzato G, Bava A: Vitamin B12 and folate depletion in cognition: a review. Neurol India 2004;52:310-318.

80 Garcia A: Cobalamin and homocysteine in older adults: do we need to test for serum levels in the work-up of dementia? Alzheimers Dement 2007;3:318-324.

$>81$ Wang HX: Vitamin B12, folate, and Alzheimer's disease. Drug Dev Res 2002;56:111122.

82 Dangour AD, Whitehouse PJ, Rafferty K, Mitchell SA, Smith L, Hawkesworth S, Vellas $\mathrm{B}$ : B-vitamins and fatty acids in the prevention and treatment of Alzheimer's disease and dementia: a systematic review. J Alzheimers Dis 2010;22:205-224.

83 Malouf R, Grimley Evans J: The effect of vitamin B6 on cognition. Cochrane Database Syst Rev 2003;(4):CD004393.

84 Balk EM, Raman G, Tatsioni A, Chung M, Lau J, Rosenberg IH: Vitamin B6, B12, and folic acid supplementation and cognitive function: a systematic review of randomized trials. Arch Intern Med 2007;167:21-30.
85 Stott DJ, MacIntosh G, Lowe GD, Rumley A, McMahon AD, Langhorne $\mathrm{P}$, Tait RC, O’Reilly DS, Spilg EG, MacDonald JB, MacFarlane PW, Westendorp RG: Randomized controlled trial of homocysteine-lowering vitamin treatment in elderly patients with vascular disease. Am J Clin Nutr 2005;82: 1320-1326.

-86 Tolonen M, Schrijver J, Westermarck T, Halme M, Tuominen SE, Frilander A, Keinonen M, Sarna S: Vitamin B6 status of Finnish elderly. Comparison with Dutch younger adults and elderly. The effect of supplementation. Int J Vitam Nutr Res 1988;58:73-77.

87 Malouf R, Grimley Evans J: Folic acid with or without vitamin B12 for the prevention and treatment of healthy elderly and demented people. Cochrane Database Syst Rev 2008;(4):CD004514.

88 Wald DS, Kasturiratne A, Simmonds M: Effect of folic acid, with or without other B vitamins, on cognitive decline: meta-analysis of randomized trials. Am J Med 2010;123: 522-527.e2

89 Malouf R, Areosa Sastre A: Vitamin B12 for cognition. Cochrane Database Syst Rev 2003;(3):CD004326.

90 Ford AH, Flicker L, McCaul K, van Bockxmeer F, Hegarty S, Hirani V, Fenner S, Almeida OP: The B-VITAGE trial: a randomized trial of homocysteine lowering treatment of depression in later life. Trials 2010; 11:8.

-91 de Benoist B: Conclusions of a WHO Technical Consultation on folate and vitamin B12 deficiencies. Food Nutr Bull 2008;29:S238S244.

-92 Murakami K, Miyake Y, Sasaki S, Tanaka K, Arakawa M: Dietary folate, riboflavin, vitamin B-6, and vitamin B-12 and depressive symptoms in early adolescence: the Ryukyus Child Health Study. Psychosom Med 2010; 72:763-768

93 Merete C, Falcon LM, Tucker KL: Vitamin B6 is associated with depressive symptomatology in Massachusetts elders. J Am Coll Nutr 2008;27:421-427.

94 Hvas AM, Juul S, Bech P, Nexo E: Vitamin B6 level is associated with symptoms of depression. Psychother Psychosom 2004;73:340343.

-95 Sanchez-Villegas A, Doreste J, Schlatter J, Pla J, Bes-Rastrollo M, Martinez-Gonzalez MA: Association between folate, vitamin $\mathrm{B}(6)$ and vitamin $\mathrm{B}(12)$ intake and depression in the SUN cohort study. J Hum Nutr Diet 2009;22: 122-133.

96 Ng TP, Feng L, Niti M, Kua EH, Yap KB: Folate, vitamin B12, homocysteine, and depressive symptoms in a population sample of older Chinese adults. J Am Geriatr Soc 2009;57: 871-876.

97 Beydoun MA, Shroff MR, Beydoun HA, Zonderman AB: Serum folate, vitamin B-12, and homocysteine and their association with depressive symptoms among U.S. adults. Psychosom Med 2010;72:862-873. 
$\checkmark 98$ Robinson D, O’Luanaigh C, Tehee E, 111 Innis SM: Dietary omega 3 fatty acids and O’Connell H, Hamilton F, Chin A, Coen R, Molloy A, Scott J, Cunningham C, Lawlor B: Associations between holotranscobalamin, vitamin B12, homocysteine and depressive symptoms in community-dwelling elders. Int J Geriatr Psychiatry 2011;26:307-313.

-99 Kamphuis MH, Geerlings MI, Grobbee DE, Kromhout D: Dietary intake of B(6-9-12) vitamins, serum homocysteine levels and their association with depressive symptoms: the Zutphen Elderly Study. Eur J Clin Nutr 2008;62:939-945.

-100 Skarupski KA, Tangney C, Li H, Ouyang B, Evans DA, Morris MC: Longitudinal association of vitamin B-6, folate, and vitamin B-12 with depressive symptoms among older adults over time. Am J Clin Nutr 2010;92: 330-335.

-101 Reynolds EH, Preece JM, Bailey J, Coppen A: Folate deficiency in depressive illness. Br J Psychiatry 1970;117:287-292.

-102 Almeida OP, McCaul K, Hankey GJ, Norman P, Jamrozik K, Flicker L: Homocysteine and depression in later life. Arch Gen Psychiatry 2008;65:1286-1294.

103 Forti P, Rietti E, Pisacane N, Olivelli V, Dalmonte E, Mecocci P, Ravaglia G: Blood homocysteine and risk of depression in the elderly. Arch Gerontol Geriatr 2010;51:21-25.

-104 Williams AL, Cotter A, Sabina A, Girard C, Goodman J, Katz DL: The role for vitamin B-6 as treatment for depression: a systematic review. Fam Pract 2005;22:532-537.

105 Ford AH, Flicker L, Thomas J, Norman P, Jamrozik K, Almeida OP: Vitamins B12, B6, and folic acid for onset of depressive symptoms in older men: results from a 2-year placebo-controlled randomized trial. J Clin Psychiatry 2008;69:1203-1209.

-106 Almeida OP, Marsh K, Alfonso H, Flicker L, Davis TM, Hankey GJ: B-vitamins reduce the long-term risk of depression after stroke: the VITATOPS-DEP trial. Ann Neurol 2010;68:503-510.

-107 Harris WS, Mozaffarian D, Lefevre M, Toner CD, Colombo J, Cunnane SC, Holden JM, Klurfeld DM, Morris MC, Whelan J: Towards establishing dietary reference intakes for eicosapentaenoic and docosahexaenoic acids. J Nutr 2009;139:804S819 S.

108 Innis SM: Omega-3 Fatty acids and neural development to 2 years of age: do we know enough for dietary recommendations? J Pediatr Gastroenterol Nutr 2009;48(suppl 1):S16-S24.

109 Hibbeln JR, Davis JM: Considerations regarding neuropsychiatric nutritional requirements for intakes of omega-3 highly unsaturated fatty acids. Prostaglandins Leukot Essent Fatty Acids 2009;81:179186.

-110 Mozaffarian D, Rimm EB: Fish intake, contaminants, and human health: evaluating the risks and the benefits. JAMA 2006;296: 1885-1899. the developing brain. Brain Res 2008;1237: 35-43.

$112 \mathrm{Al} \mathrm{MD}$, van Houwelingen AC, Kester AD, Hasaart TH, de Jong AE, Hornstra G: Maternal essential fatty acid patterns during normal pregnancy and their relationship to the neonatal essential fatty acid status. $\mathrm{Br} J$ Nutr 1995;74:55-68.

113 Otto SJ, van Houwelingen AC, BadartSmook A, Hornstra G: Changes in the maternal essential fatty acid profile during early pregnancy and the relation of the profile to diet. Am J Clin Nutr 2001;73:302307

114 Elmadfa I, Kornsteiner M: Dietary fat intake - a global perspective. Ann Nutr Metab 2009;54(suppl 1):8-14.

115 Innis SM: Fatty acids and early human development. Early Hum Dev 2007;83:761766.

116 Uauy R, Castillo C: Lipid requirements of infants: implications for nutrient composition of fortified complementary foods. J Nutr 2003;133:2962S-2972S.

117 Uauy R, Dangour AD: Fat and fatty acid requirements and recommendations for infants of $0-2$ years and children of $2-18$ years. Ann Nutr Metab 2009;55:76-96.

118 Kris-Etherton PM, Taylor DS, Yu-Poth S, Huth P, Moriarty K, Fishell V, Hargrove RL, Zhao G, Etherton TD: Polyunsaturated fatty acids in the food chain in the United States. Am J Clin Nutr 2000;71:179S-188S.

119 Sanders TA: Polyunsaturated fatty acids in the food chain in Europe. Am J Clin Nutr 2000;71:176S-178S.

120 Meyer BJ, Mann NJ, Lewis JL, Milligan GC, Sinclair AJ, Howe PR: Dietary intakes and food sources of omega- 6 and omega- 3 polyunsaturated fatty acids. Lipids 2003;38: 391-398.

121 Ian Givens D, Gibbs RA: Current intakes of EPA and DHA in European populations and the potential of animal-derived foods to increase them. Proc Nutr Soc 2008;67: 273-280.

122 The Netherlands Nutrition Centre: Zo eet Nederland, 1998: resultaten van de Voedselconsumptiepeiling 1998 (Results of the Dutch national food consumption survey 1998). The Hague, Voorlichtingsbureau voor de Voeding (The Netherlands Nutrition Centre), 1998.

123 Oomen CM, Feskens EJ, Rasanen L, Fidanza F, Nissinen AM, Menotti A, Kok FJ, Kromhout D: Fish consumption and coronary heart disease mortality in Finland, Italy, and The Netherlands. Am J Epidemiol 2000;151:999-1006.

124 Soderberg M, Edlund C, Kristensson K, Dallner G: Lipid compositions of different regions of the human brain during aging. J Neurochem 1990;54:415-423.
125 Giusto NM, Salvador GA, Castagnet PI, Pasquare SJ, Ilincheta de Boschero MG: Age-associated changes in central nervous system glycerolipid composition and metabolism. Neurochem Res 2002;27:15131523.

126 Conquer JA, Tierney MC, Zecevic J, Bettger WJ, Fisher RH: Fatty acid analysis of blood plasma of patients with Alzheimer's disease, other types of dementia, and cognitive impairment. Lipids 2000;35:1305-1312.

127 Tully AM, Roche HM, Doyle R, Fallon C, Bruce I, Lawlor B, Coakley D, Gibney MJ: Low serum cholesteryl ester-docosahexaenoic acid levels in Alzheimer's disease: a case-control study. Br J Nutr 2003;89:483489.

128 Huang TL: Omega-3 fatty acids, cognitive decline, and Alzheimer's disease: a critical review and evaluation of the literature. J Alzheimers Dis 2010;21:673-690.

129 Cunnane SC, Plourde M, Pifferi F, Begin M, Feart C, Barberger-Gateau P: Fish, docosahexaenoic acid and Alzheimer's disease. Prog Lipid Res 2009;48:239-256.

130 Hadders-Algra M: Prenatal long-chain polyunsaturated fatty acid status: the importance of a balanced intake of docosahexaenoic acid and arachidonic acid. J Perinat Med 2008;36:101-109.

131 Ryan AS, Astwood JD, Gautier S, Kuratko CN, Nelson EB, Salem N Jr: Effects of longchain polyunsaturated fatty acid supplementation on neurodevelopment in childhood: a review of human studies. Prostaglandins Leukot Essent Fatty Acids 2010; 82:305-314.

132 Eilander A, Hundscheid DC, Osendarp SJ, Transler C, Zock PL: Effects of n-3 long chain polyunsaturated fatty acid supplementation on visual and cognitive development throughout childhood: a review of human studies. Prostaglandins Leukot Essent Fatty Acids 2007;76:189-203.

133 Hoffman DR, Boettcher JA, DiersenSchade DA: Toward optimizing vision and cognition in term infants by dietary docosahexaenoic and arachidonic acid supplementation: a review of randomized controlled trials. Prostaglandins Leukot Essent Fatty Acids 2009;81:151-158.

134 Simmer K: Longchain polyunsaturated fatty acid supplementation in infants born at term. Cochrane Database Syst Rev 2001;(4):CD000376.

135 Simmer K, Patole SK, Rao SC: Longchain polyunsaturated fatty acid supplementation in infants born at term. Cochrane Database Syst Rev 2008;(1):CD000376.

136 Ryan AS, Nelson EB: Assessing the effect of docosahexaenoic acid on cognitive functions in healthy, preschool children: a randomized, placebo-controlled, double-blind study. Clin Pediatr (Phila) 2008;47:355362 . van de Rest/van Hooijdonk/Doets/ Schiepers/Eilander/de Groot 
137 Dalton A, Wolmarans P, Witthuhn RC, van Stuijvenberg ME, Swanevelder SA, Smuts CM: A randomised control trial in schoolchildren showed improvement in cognitive function after consuming a bread spread, containing fish flour from a marine source. Prostaglandins Leukot Essent Fatty Acids 2009;80:143-149.

138 Kennedy DO, Jackson PA, Elliott JM, Scholey $\mathrm{AB}$, Robertson $\mathrm{BC}$, Greer J, Tiplady B, Buchanan T, Haskell CF: Cognitive and mood effects of 8 weeks' supplementation with $400 \mathrm{mg}$ or $1,000 \mathrm{mg}$ of the omega-3 essential fatty acid docosahexaenoic acid (DHA) in healthy children aged 10-12 years. Nutr Neurosci 2009;12:48-56.

139 Kirby A, Woodward A, Jackson S, Wang Y, Crawford MA: A double-blind, placebocontrolled study investigating the effects of omega-3 supplementation in children aged 8-10 years from a mainstream school population. Res Dev Disabil 2010;31:718-730.

140 McNamara RK, Able J, Jandacek R, Rider T, Tso P, Eliassen JC, Alfieri D, Weber W, Jarvis K, DelBello MP, Strakowski SM, Adler CM: Docosahexaenoic acid supplementation increases prefrontal cortex activation during sustained attention in healthy boys: a placebo-controlled, dose-ranging, functional magnetic resonance imaging study. Am J Clin Nutr 2010;91:1060-1067.

- 141 Muthayya S, Eilander A, Transler C, Thomas T, van der Knaap HC, Srinivasan K, van Klinken BJ, Osendarp SJ, Kurpad AV: Effect of fortification with multiple micronutrients and n-3 fatty acids on growth and cognitive performance in Indian schoolchildren: the CHAMPION (Children's Health and Mental Performance Influenced by Optimal Nutrition) Study. Am J Clin Nutr 2009;89:1766-1775.

- 142 Osendarp SJ, Baghurst KI, Bryan J, Calvaresi E, Hughes D, Hussaini M, Karyadi SJ, van Klinken BJ, van der Knaap HC, Lukito W, Mikarsa W, Transler C, Wilson C: Effect of a 12-mo micronutrient intervention on learning and memory in well-nourished and marginally nourished school-aged children: 2 parallel, randomized, placebocontrolled studies in Australia and Indonesia. Am J Clin Nutr 2007;86:1082-1093.

143 de Groot RH, Hornstra G, Jolles J: Exploratory study into the relation between plasma phospholipid fatty acid status and cognitive performance. Prostaglandins Leukot Essent Fatty Acids 2007;76:165-172.

144 Cederholm T, Palmblad J: Are omega-3 fatty acids options for prevention and treatment of cognitive decline and dementia? Curr Opin Clin Nutr Metab Care 2010;13: 150-155.
145 Kesse-Guyot E, Peneau S, Ferry M, Jeandel C, Hercberg S, Galan P; SU.VI.MAX 2 Research Group: Thirteen-year prospective study between fish consumption, longchain n-3 fatty acid intakes and cognitive function. J Nutr Health Aging 2011;15:115120.

146 Lim W, Gammack J, Van Niekerk J, Dangour A: Omega 3 fatty acid for the prevention of dementia. Cochrane Database Syst Rev 2006;(1):CD005379.

147 Terano T, Fujishiro S, Ban T, Yamamoto K, Tanaka T, Noguchi Y, Tamura Y, Yazawa K, Hirayama T: Docosahexaenoic acid supplementation improves the moderately severe dementia from thrombotic cerebrovascular diseases. Lipids 1999;34(suppl): S345-S346.

148 Yehuda S, Rabinovtz S, Carasso RL, Mostofsky DI: Essential fatty acids preparation (SR-3) improves Alzheimer's patients quality of life. Int J Neurosci 1996;87:141-149.

149 van de Rest O, Geleijnse JM, Kok FJ, van Staveren WA, Dullemeijer C, Olderikkert MG, Beekman AT, de Groot CP: Effect of fish oil on cognitive performance in older subjects: a randomized, controlled trial. Neurology 2008;71:430-438.

150 Freund-Levi Y, Eriksdotter-Jonhagen M, Cederholm T, Basun H, Faxen-Irving G, Garlind A, Vedin I, Vessby B, Wahlund LO, Palmblad J: Omega-3 fatty acid treatment in 174 patients with mild to moderate Alzheimer disease: OmegAD study: a randomized double-blind trial. Arch Neurol 2006;63:1402-1408.

151 Chiu CC, Su KP, Cheng TC, Liu HC, Chang CJ, Dewey ME, Stewart R, Huang SY: The effects of omega-3 fatty acids monotherapy in Alzheimer's disease and mild cognitive impairment: a preliminary randomized double-blind placebo-controlled study. Prog Neuropsychopharmacol Biol Psychiatry 2008;32:1538-1544.

152 Johnson EJ, McDonald K, Caldarella SM, Chung HY, Troen AM, Snodderly DM: Cognitive findings of an exploratory trial of docosahexaenoic acid and lutein supplementation in older women. Nutr Neurosci 2008;11:75-83.

$>153$ Fotuhi M, Mohassel P, Yaffe K: Fish consumption, long-chain omega-3 fatty acids and risk of cognitive decline or Alzheimer disease: a complex association. Nat Clin Pract Neurol 2009;5:140-152.

154 Quinn JF: A clinical trial of docosahexaenoic acid (DHA) for the treatment of Alzheimer's Disease. Alzheimers Dement 2009;5:P84.

155 Yurko-Mauro K: Cognitive and cardiovascular benefits of docosahexaenoic acid in aging and cognitive decline. Curr Alzheimer Res 2010;7:190-196.
156 Dangour AD, Allen E, Elbourne D, Fasey N, Fletcher AE, Hardy P, Holder GE, Knight R, Letley L, Richards M, Uauy R: Effect of 2-y n-3 long-chain polyunsaturated fatty acid supplementation on cognitive function in older people: a randomized, double-blind, controlled trial. Am J Clin Nutr 2010;91: 1725-1732.

157 Gillette-Guyonnet S, Andrieu S, Dantoine T, Dartigues JF, Touchon J, Vellas B: Commentary on 'A roadmap for the prevention of dementia II. Leon Thal Symposium 2008.' The Multidomain Alzheimer Preventive Trial (MAPT): a new approach to the prevention of Alzheimer's disease. Alzheimers Dement 2009;5:114-121.

-158 Ramakrishnan U, Imhoff-Kunsch B, DiGirolamo AM: Role of docosahexaenoic acid in maternal and child mental health. Am J Clin Nutr 2009;89:958S-962S.

159 Mamalakis G, Kiriakakis M, Tsibinos G, Kafatos A: Depression and adipose polyunsaturated fatty acids in an adolescent group. Prostaglandins Leukot Essent Fatty Acids 2004;71:289-294.

160 Mamalakis G, Kiriakakis M, Tsibinos G, Hatzis C, Flouri S, Mantzoros C, Kafatos A: Depression and serum adiponectin and adipose omega-3 and omega- 6 fatty acids in adolescents. Pharmacol Biochem Behav 2006;85:474-479.

161 Nemets H, Nemets B, Apter A, Bracha Z, Belmaker RH: Omega-3 treatment of childhood depression: a controlled, doubleblind pilot study. Am J Psychiatry 2006;163: 1098-1100.

162 Osher Y, Belmaker RH: Omega-3 fatty acids in depression: a review of three studies. CNS Neurosci Ther 2009;15:128-133.

163 Hibbeln JR: Fish consumption and major depression. Lancet 1998;351:1213.

164 Appleton KM, Rogers PJ, Ness AR: Is there a role for $\mathrm{n}-3$ long-chain polyunsaturated fatty acids in the regulation of mood and behaviour? A review of the evidence to date from epidemiological studies, clinical studies and intervention trials. Nutr Res Rev 2008;21:13-41.

165 Bountziouka V, Polychronopoulos E, Zeimbekis A, Papavenetiou E, Ladoukaki E, Papairakleous N, Gotsis E, Metallinos G, Lionis C, Panagiotakos D: Long-term fish intake is associated with less severe depressive symptoms among elderly men and women: the MEDIS (MEDiterranean ISlands Elderly) epidemiological study. J Aging Health 2009;21:864-880.

166 Murakami K, Mizoue T, Sasaki S, Ohta M, Sato M, Matsushita Y, Mishima N: Dietary intake of folate, other B vitamins, and omega-3 polyunsaturated fatty acids in relation to depressive symptoms in Japanese adults. Nutrition 2008;24:140-147. 
167 Colangelo LA, He K, Whooley MA, Daviglus ML, Liu K: Higher dietary intake of long-chain omega-3 polyunsaturated fatty acids is inversely associated with depressive symptoms in women. Nutrition 2009;25: 1011-1019.

168 Sanchez-Villegas A, Henriquez P, Figueiras A, Ortuno F, Lahortiga F, Martinez-Gonzalez MA: Long chain omega-3 fatty acids intake, fish consumption and mental disorders in the SUN cohort study. Eur J Nutr 2007;46:337-346.

169 Lin PY, Huang SY, Su KP: A meta-analytic review of polyunsaturated fatty acid compositions in patients with depression. Biol Psychiatry 2010;68:140-147.

170 Conklin SM, Manuck SB, Yao JK, Flory JD, Hibbeln JR, Muldoon MF: High omega-6 and low omega-3 fatty acids are associated with depressive symptoms and neuroticism. Psychosom Med 2007;69:932-934.
171 Schiepers OJ, de Groot RH, Jolles J, van Boxtel MP: Plasma phospholipid fatty acid status and depressive symptoms: association only present in the clinical range. J Affect Disord 2009;118:209-214.

172 Appleton KM, Gunnell D, Peters TJ, Ness AR, Kessler D, Rogers PJ: No clear evidence of an association between plasma concentrations of n-3 long-chain polyunsaturated fatty acids and depressed mood in a nonclinical population. Prostaglandins Leukot Essent Fatty Acids 2008;78:337-342.

173 Appleton KM, Rogers PJ, Ness AR: Updated systematic review and meta-analysis of the effects of $n-3$ long-chain polyunsaturated fatty acids on depressed mood. Am J Clin Nutr 2010;91:757-770.

174 Martins JG: EPA but not DHA appears to be responsible for the efficacy of omega-3 long chain polyunsaturated fatty acid supplementation in depression: evidence from a meta-analysis of randomized controlled trials. J Am Coll Nutr 2009;28:525-542.
175 Rondanelli M, Giacosa A, Opizzi A, Pelucchi C, La Vecchia C, Montorfano G, Negroni M, Berra B, Politi P, Rizzo AM: Effect of omega-3 fatty acids supplementation on depressive symptoms and on health-related quality of life in the treatment of elderly women with depression: a double-blind, placebo-controlled, randomized clinical trial. J Am Coll Nutr 2010;29:55-64.

176 Hadders-Algra M, Bouwstra H, van Goor SA, Dijck-Brouwer DA, Muskiet FA: Prenatal and early postnatal fatty acid status and neurodevelopmental outcome. J Perinat Med 2007;35(suppl 1):S28-S34

177 Benton D: The influence of children's diet on their cognition and behavior. Eur J Nutr 2008;47(suppl 3):25-37. van de Rest/van Hooijdonk/Doets/ Schiepers/Eilander/de Groot 